\title{
Dispersed Conducting Polymer Nanocomposites with Glucose Oxidase and Gold Nanoparticles for the Design of Enzymatic Glucose Biosensors
}

\author{
Natalija German ${ }^{1,2}$, Almira Ramanaviciene ${ }^{1,2}$ (D) and Arunas Ramanavicius ${ }^{3,4, *(D)}$ \\ 1 Department of Immunology, State Research Institute Centre for Innovative Medicine, Santariskiu 5, \\ LT-08406 Vilnius, Lithuania; natalija.german@imcentras.lt (N.G.); almira.ramanaviciene@chf.vu.lt (A.R.) \\ 2 NanoTechnas-Center of Nanotechnology and Materials Science, Faculty of Chemistry and Geosciences, \\ Vilnius University, LT-03225 Vilnius, Lithuania \\ 3 Department of Physical Chemistry, Faculty of Chemistry and Geosciences, Vilnius University, \\ Naugarduko 24, LT-03225 Vilnius, Lithuania \\ 4 Division of Materials Science and Electronics, State Scientific Research Institute Center for Physical Sciences \\ and Technology, Savanoriu ave. 231, LT-02300 Vilnius, Lithuania \\ * Correspondence: arunas.ramanavicius@chf.vu.lt
}

Citation: German, N.;

Ramanaviciene, A.; Ramanavicius, A. Dispersed Conducting Polymer

Nanocomposites with Glucose

Oxidase and Gold Nanoparticles for the Design of Enzymatic Glucose

Biosensors. Polymers 2021, 13, 2173.

https://doi.org/10.3390/

polym 13132173

Academic Editor: Jinming Hu

Received: 12 June 2021

Accepted: 22 June 2021

Published: 30 June 2021

Publisher's Note: MDPI stays neutral with regard to jurisdictional claims in published maps and institutional affiliations.

Copyright: (c) 2021 by the authors. Licensee MDPI, Basel, Switzerland. This article is an open access article distributed under the terms and conditions of the Creative Commons Attribution (CC BY) license (https:// creativecommons.org/licenses/by/ $4.0 /)$.

\begin{abstract}
Biosensors for the determination of glucose concentration have a great significance in clinical diagnosis, and in the food and pharmaceutics industries. In this research, short-chain polyaniline (PANI) and polypyrrole (Ppy)-based nanocomposites with glucose oxidase (GOx) and $6 \mathrm{~nm}$ diameter AuNPs $\left(\operatorname{AuNPs}_{(6 \mathrm{~nm})}\right)$ were deposited on the graphite rod (GR) electrode followed by the immobilization of GOx. Optimal conditions for the modification of GR electrodes by conducting polymer-based nanocomposites and GOx were elaborated. The electrodes were investigated by cyclic voltammetry and constant potential amperometry in the presence of the redox mediator phenazine methosulfate (PMS). The improved enzymatic biosensors based on GR/PANI-AuNPs $(6 \mathrm{~nm})^{-}$ GOx/GOx and GR/Ppy-AuNPs $(6 \mathrm{~nm})$-GOx/GOx electrodes were characterized by high sensitivity (65.4 and $\left.55.4 \mu \mathrm{A} \mathrm{mM}^{-1} \mathrm{~cm}^{-2}\right)$, low limit of detection $\left(0.070\right.$ and $\left.0.071 \mathrm{mmol} \mathrm{L}^{-1}\right)$, wide linear range (up to $16.5 \mathrm{mmol} \mathrm{L}^{-1}$ ), good repeatability (RSD 4.67 and $5.89 \%$ ), and appropriate stability (half-life period $\left(\tau_{1 / 2}\right)$ was 22 and 17 days, respectively). The excellent anti-interference ability to ascorbic and uric acids and successful practical application for glucose determination in serum samples was presented for GR/PANI-AuNPs $(6 \mathrm{~nm})$-GOx/GOx electrode.
\end{abstract}

Keywords: conducting polymers; glucose biosensor; glucose oxidase; gold nanoparticles; graphite rod electrode; interference by ascorbic and uric acids; polyaniline; polypyrrole; amperometry; bioelectrochemistry

\section{Introduction}

The design and wide application of electrochemical biosensors in nanoscience, nanotechnology, medicine, environmental, and food monitoring has significantly intensified during the past decade [1-6]. The advanced technology has enabled the construction of highly sensitive, selective, customizable, and portable sensors for the determination of glucose [3-9]. The development of glucose biosensors has great significance in the diagnosis and control of diabetes mellitus, which is considered a worldwide public health problem, which increases the risk of heart disease, kidney failure, blindness, postoperative and wound infections $[2-5,10,11]$. Diabetes is diagnosed in seven million people every year and globally one person is killed every $10 \mathrm{~s}$ due to this disease [2]. Glucose biosensors have been become widespread due to the high speed, accuracy, and simplicity of analyte's level monitoring in the blood [2,3,6,11,12], saliva [4], tears and sweat $[10,13]$.

Recently, enzymes have been used for the design of enzymatic biofuel cells [14-18] and biosensors $[8,9,13,16-20]$. During electrochemical processes, glucose oxidase (GOx) does 
not directly transfer electrons towards conventional electrode materials, because a thick protein layer surrounds the active site of GOx based on the flavin adenine dinucleotide (FAD) redox center, and this protein layer is forming the intrinsic barrier to charge transfer from the active site $[10,15,21]$. Therefore, in many GOx-related researches, charge transfer is accelerated by soluble redox mediators (e.g., phenazine methosulfate (PMS)) $[8,10]$. In the presence of oxygen in the solution, GOx immobilized on graphite electrodes catalyzes the oxidation of glucose into gluconolactone following hydrolysis to gluconic acid and provides the selectivity for the electrochemical sensor $[2,14,21-25]$. Usually the oxidation of glucose is proceeded at the potential, which is slightly more positive than the redox potential $(-0.44 \mathrm{~V})$ of FAD cofactor located in the active site of GOx, and this redox potential is sufficient for the reduction of dissolved oxygen $[22,23,26]$. The development of miniaturized enzymatic biosensors with the size ranging from several millimeters down to a few micrometers requires the combination of knowledge in electrochemistry, material science, polymer synthesis, enzymology and biological chemistry $[4,20]$.

Major fundamental and nanotechnological advances have opened new horizons for the application of nanomaterials [10,20] and hybrid composites (carbon nanotubes [25], carbon nanotubes/graphene oxide [9], chitosan/gold nanoparticles [27]) in bioanalytical chemistry [10]. Compositions of nanomaterials $\left(\mathrm{Ag}, \mathrm{Au}, \mathrm{MnO}_{2}, \mathrm{SiO}_{2}, \mathrm{ZnO}, \mathrm{ZrO}_{2}\right.$, and many others), which are characterized by variable sizes and shapes, have been considered as unique materials for the immobilization of enzymes and have been used for the design of electrochemical biosensors [1,22-24,27-29]. The nature of the interaction between working electrodes, gold nanoparticles (AuNPs) and proteins has not been fully investigated and the influence of surface to volume ratio, high energy, and very active AuNPs as electron transfer between a redox protein and the surface of an electrode occurs in several ways [1,30]. Firstly, AuNPs are able to strongly interact with some parts of protein molecules: in such a way, proteins become immobilized on the surface of AuNPs. If the redox active sites of proteins are at a sufficiently low distance from AuNPs surface, then the electron transfer can proceed much easier [30,31]. AuNPs are characterized by high conductivity and biocompatibility, they are able to improve the sensitivity and stability of biosensors by catalyzing the oxidation of $\mathrm{H}_{2} \mathrm{O}_{2}$ and the facilitation of accepted electron transfer towards the electrode $[7,10,22]$. GOx is able to catalyze the reduction of $\mathrm{AuCl}_{4}{ }^{-}$ions and form of metallic AuNPs, the size of which depends on the kinetics of the nucleation reaction [26].

$\pi-\pi$ conjugated polymers (including polyaniline (PANI) and polypyrrole (Ppy)), which can be synthesized via chemical or electrochemical oxidation of monomers, are used for the development of rechargeable batteries, smart windows, light emitting diodes, transistors, sensors and etc. [32]. These conjugated polymers also are characterized by excellent electrical properties, therefore, in some particular cases they may act as redox mediators and facilitate the transfer of electrons to the electrode $[1,16,17,33]$. The formation of charge carriers such as polarons, bipolarons, and solitons is leaded due to electrons addition or extraction from the delocalized $\pi$-boned polymer backbone [32,34]. The colors of polymers depend on their redox states, e.g., PANI changes the color from yellow to green, blue, and violet [34], and Ppy exists in intensive black color due to the delocalized $\pi$ electron system of the doped polymer [35]. The conductivity of $\pi-\pi$ conjugated polymers can be improved by electrochemical doping to induce an insulator-to-conductor transition in these polymers [34], and both $n$-type and $p$-type charge carriers can be involved in charge transfer within $\pi-\pi$ conjugated polymers. PANI is electrically conducting and electroactive in protonated form at low $\mathrm{pH}$ values, but at $\mathrm{pH} 3$ or 4 it is insulating and electrochemically inactive [32]. During the enzymatic formation of $\pi-\pi$ conjugated polymers, the monomer is 'attacked' by a radical cation induced by $\mathrm{H}_{2} \mathrm{O}_{2}$ and this process is leading towards the polymerization reaction [32,36]. The $\pi-\pi$ conjugated structures formed between the redox center of the enzyme and the electrode increase the efficiency of the charge transfer in this structure $[10,16,17,33]$.

PANI and Ppy were combined with electroactive AuNPs and GOx, and were integrated as a structure suitable for the development of biosensors dedicated for the monitor- 
ing of glucose $[1,29]$. The hydrophilic functional groups (e.g., $-\mathrm{NH}_{2}$ ) of proteins paved the way to the interaction of AuNPs with these proteins [30,37]. The biosensors based on $\pi-\pi$ conjugated polymer nanocomposites presented the best sensing performance due to the effective 'contact' between the enzyme and electrode. Additionally, such types of biosensors are more resistant to some interfering materials $[4,29,34]$. The developed glucose biosensor based on graphite rod (GR) electrode modified by an overoxidized polypyrrole (OOPpy $\left._{(300 \mathrm{~s})}\right)$ film, nano Au and GOx and operating in the presence of redox mediator was characterized by the sensitivity of $3.07 \mu \mathrm{AmM}^{-1} \mathrm{~cm}^{-2}$ [29]. The glucose biosensor based on GR electrode modified with electrochemically deposited $13 \mathrm{~nm}$ AuNPs, immobilized GOx and formed Ppy film exhibited sensitivity to glucose of $21.7 \mu \mathrm{A} \mathrm{mM}^{-1} \mathrm{~cm}^{-2}$ in the presence of redox mediator [38]. Biosensor based on GR electrode modified by long-chain Ppy nanocomposites containing GOx and $\mathrm{AuCl}_{4}{ }^{-}$ions was characterized by a sensitivity of $4.31 \mathrm{~mA} \mathrm{mM}^{-1} \mathrm{~cm}^{-2}$ and narrow linear range (up to $0.70 \mathrm{mmol} \mathrm{L}^{-1}$ ) in the presence of redox mediator [39].

The main aim of the presented study was to improve the analytical characteristics of amperometric glucose biosensors based on conducting polymer nanocomposites with embedded GOx and $6 \mathrm{~nm}$ diameter AuNPs $\left(\operatorname{AuNPs}_{(6 \mathrm{~nm})}\right)$. For this reason, short chain polymer nanocomposites (PANI-AuNPs $(6 \mathrm{~nm})-\mathrm{GOx}$ and Ppy-AuNPs $(6 \mathrm{~nm})-\mathrm{GOx}$ ) were prepared, dispersing $\pi-\pi$ conjugated polymer-based nanocomposites in the solution by ultrasound. An additional layer of GOx was formed over GR electrode pre-modified with dispersed conducting polymer nanocomposites.

\section{Materials and Methods}

\subsection{Materials}

Glucose oxidase (EC 1.1.3.4, type VII, from Aspergillus niger, 201 units $\mathrm{mg}^{-1}$ protein) and $\mathrm{D}-(+)$-glucose, $\mathrm{D}(-)$-fructose, $\mathrm{D}(+)$-mannose, $\mathrm{D}(+)$-galactose, $\mathrm{D}(+)$-xylose, $\mathrm{D}(+)$ saccharose were obtained from Fluka (Buchs, Switzerland) and Carl Roth GmbH+Co.KG (Karlsruhe, Germany). Tetrachloroauric acid and tannic acid were purchased from Alfa Aesar GmbH\&Co KG and Carl Roth GmbH + Co (Karlsruhe, Germany), sodium citratefrom Penta (Praha, Czech Republic). $0.05 \mathrm{~mol} \mathrm{~L}^{-1}$ solution of sodium acetate (SA) buffer with $0.1 \mathrm{~mol} \mathrm{~L}^{-1}$ potassium chloride $(\mathrm{KCl})$ was prepared from sodium acetate trihydrate and potassium chloride, whose were obtained from Reanal (Budapest, Hungary) and Lachema (Neratovice, Czech Republic). Aniline and sodium hydroxide were purchased from Merck KGaA (Darmstadt, Germany), pyrrole-from Acros Organics (New Jersey, NJ, USA), graphite rod (GR, $\varnothing=3 \mathrm{~mm}$ ) and hydrochloric acid-from Sigma-Aldrich (Saint Louis, MO, USA), $\alpha$ alumina powder $\left(\mathrm{Al}_{2} \mathrm{O}_{3}, 0.3 \mu \mathrm{m}\right.$, Type $\left.\mathrm{N}\right)$-from Electron Microscopy Sciences (Hatfield, MA, USA). The solution of $25 \%$ glutaraldehyde was obtained from Fluka Chemie GmbH (Buchs, Switzerland), phenazine methosulfate, L-ascorbic acid (AA) and uric acid (UA)—from AppliChem GmbH (Darmstadt, Germany). $2.3 \times 10^{16}$ particles $\mathrm{L}^{-1}$ of $\operatorname{AuNPs}_{(6 \mathrm{~nm})}$ were prepared as was described in previous research [28].

\subsection{The Polymerization, Separation and Dispersion of Polymer-Based Nanocomposites}

PANI-GOx, Ppy-GOx, PANI-AuNPs $s_{(6 \mathrm{~nm})}{ }^{-G O x}$ and Ppy-AuNPs $(6 \mathrm{~nm})$-GOx nanocomposites were synthesized for 2 days and separated according to previously described methodology [39-41]. PANI-AuNPs $s_{(6 \mathrm{~nm})}-\mathrm{GOx}$ and Ppy-AuNPs $(6 \mathrm{~nm})-\mathrm{GOx}$ were tending to agglomerate according to previously reported results $[39,42]$. In the presence of GOx and $\mathrm{AuNPs}_{(6 \mathrm{~nm})}$ aniline and pyrrole were polymerized into the spherical particles. In the presence of pyrrole, nanocomposites were formed layered structure.

The separation of polymer nanocomposites from the polymerization solution was performed at $14.6 \times 10^{3} \mathrm{~g}$ for $8 \mathrm{~min}$ using IEC CL31R Multispeed centrifuge (ZI Aze Bellitournt, France). After then, the collected polymer-based nanocomposites were dispersed in $40 \mu \mathrm{L}$ of SA buffer, pH 6.0, using the ultrasonic bath (Bandelin electronic, Germany) to achieve short chain polymers. 


\subsection{The Preparation of Graphite Rod Electrode and Modification by Polymer-Based Nanocomposites}

Working electrode - graphite rod (surface area $0.071 \mathrm{~cm}^{2}$ ) was cut, polished using fine emery paper and by humid $\mathrm{Al}_{2} \mathrm{O}_{3}$, washed, and dried at $+20 \pm 2{ }^{\circ} \mathrm{C}$. Then, GR was placed into a silicone tube. $0.43 \mu \mathrm{L} \mathrm{mm}$ m $^{-2}$ of dispersed polymer nanocomposites were deposited on CR electrode. Then $3 \mu \mathrm{L}$ of $25 \mathrm{mg} \mathrm{mL}^{-1} \mathrm{GOx}$ were immobilized on a graphite rod electrode modified by polymer nanocomposite. After the evaporation of water at room temperature, the prepared working electrode was stored for $15 \mathrm{~min}$ in a closed vessel over a $25 \%$ solution of glutaraldehyde at $+20 \pm 2{ }^{\circ} \mathrm{C}$, which covalently cross-linked the enzyme adsorbed on the polymer nanocomposites deposited on the GR [43].

\subsection{Application of Glucose Biosensor Based on GR/PANI-AuNPs (6 $\mathrm{nm})-G O x / G O x$ Electrode for Glucose Detection in the Serum Sample}

The selectivity tests of glucose biosensor to interfering and electroactive species and the electrochemical determination of glucose concentration in diluted (1:10) serum sample using GR/PANI-AuNPs $(6 \mathrm{~nm})$-GOx/GOx electrode was performed according to a methodology presented previously [39]. The influence of other sugars on the current response generated by biosensor was tested in serum sample containing $10.0 \mathrm{mmol} \mathrm{L}^{-1}$ of glucose in the absence and presence of $1.00 \mathrm{mmol} \mathrm{L}^{-1}$ fructose, mannose, galactose, xylose, and saccharose. To investigate the effect of AA and UA on the GR/PANI-AuNPs $(6 \mathrm{~nm})^{-}$ GOx/GOx electrode, serum samples with $10.0 \mathrm{mmol} \mathrm{L}^{-1}$ of glucose; $10.0 \mathrm{mmol} \mathrm{L}^{-1}$ of glucose and $0.01,0.10$ or $0.20 \mathrm{mmol} \mathrm{L}^{-1}$ of $\mathrm{AA} ; 10.0 \mathrm{mmol} \mathrm{L}^{-1}$ of glucose and $0.01,0.05$ or $0.10 \mathrm{mmol} \mathrm{L}^{-1}$ of UA were used.

\subsection{Electrochemical and Statistical Evaluations of GR/PANI-GOx/GOx, GR/Ppy-GOx/GOx,

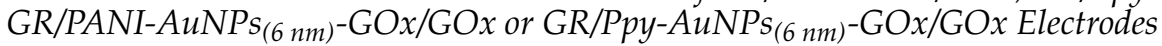

Electrochemical measurements were performed by the computerized potentiostat PGSTAT 302/Autolab from EcoChemie (Utrecht, Netherlands) with GPES 4.9 software. GR/PANI-GOx/GOx, GR/Ppy-GOx/GOx, GR/PANI-AuNPs $(6 \mathrm{~nm})$-GOx/GOx or GR/Ppy$\operatorname{AuNPs}_{(6 \mathrm{~nm})}-\mathrm{GOx} / \mathrm{GOx}$ electrodes were switched into electrochemical cell a working electrodes, $2 \mathrm{~cm}^{2}$ platinum electrode was used as a counter electrode and $\mathrm{Ag} / \mathrm{AgCl}_{(3 \mathrm{~mol} \mathrm{~L}} \mathrm{L}^{-1}$ $\mathrm{KCl}$ ) from Metrhom (Herisau, Switzerland) - as a reference electrode.

The registration of glucose was performed at $+0.30 \mathrm{~V} \mathrm{vs}$. $\mathrm{Ag} / \mathrm{AgCl}_{\left(3 \mathrm{~mol}^{-1} \mathrm{KCl}\right)}$ using amperometry in stirred (1400 rpm) by a magnetic stirrer IKA from Werke GmbH \& Co. KG (Staufen, Germany) solution of $0.05 \mathrm{~mol} \mathrm{~L}^{-1} \mathrm{SA}$ buffer, pH 6.0, containing $0.1 \mathrm{~mol} \mathrm{~L}^{-1} \mathrm{KCl}$ and in the presence of $6 \mathrm{mmol} \mathrm{L}^{-1} \mathrm{PMS}$ as soluble redox mediator. Cyclic voltammograms were registered at potential diapason from -0.60 to $+0.80 \mathrm{~V} \mathrm{vs}$. $\mathrm{Ag} / \mathrm{AgCl}_{\left(3 \mathrm{~mol} \mathrm{~L}^{-1} \mathrm{KCl}\right)}$ at a potential sweep rate of $0.100 \mathrm{~V} \mathrm{~s}^{-1}$ in an unstirred solution of $0.05 \mathrm{~mol} \mathrm{~L}^{-1} \mathrm{SA}$ buffer, $\mathrm{pH}$ 6.0, containing $0.1 \mathrm{~mol} \mathrm{~L}^{-1} \mathrm{KCl}$ and in the presence $6 \mathrm{mmol} \mathrm{L}^{-1}$ of PMS.

The sample of the serum was diluted (1:10) in $0.05 \mathrm{~mol} \mathrm{~L}^{-1} \mathrm{SA}, \mathrm{pH} 6.0$, with $0.1 \mathrm{~mol} \mathrm{~L}^{-1}$ $\mathrm{KCl}$ and centrifuged within $8 \mathrm{~min}\left(14.6 \times 10^{3} \mathrm{~g}\right)$. All investigations were performed with biosensors based on GR/PANI-AuNPs $s_{(6 \mathrm{~nm})}$-GOx/GOx electrode. The electrochemical measurements were applied in $10 \times$ diluted serum sample with $10.0 \mathrm{mmol} \mathrm{L}^{-1}$ of glucose before and after the addition of $1.00 \mathrm{mmol} \mathrm{L}^{-1}$ fructose, mannose, galactose, xylose and saccharose. To evaluate the influence of ascorbic and uric acids on the developed biosensor, the analytical signals of glucose were registered in the solutions of $10 \times$ diluted serum sample with: $10.0 \mathrm{mmol} \mathrm{L}^{-1}$ of glucose; $10.0 \mathrm{mmol} \mathrm{L}^{-1}$ of glucose and $0.01,0.10$ and $0.20 \mathrm{mmol} \mathrm{L}^{-1}$ of AA; $10.0 \mathrm{mmol} \mathrm{L}^{-1}$ of glucose and $0.01,0.05$ and $0.10 \mathrm{mmol} \mathrm{L}^{-1}$ of UA.

The parameters of Michaelis-Menten kinetics (the difference of maximal current generated during the enzymatic reaction $\left(\Delta I_{\max }\right)$ and the apparent Michaelis constant $\left.\left(K_{\mathrm{M}}\right)\right)$ and the limit of detection (LOD) were estimated by SigmaPlot software 12.5.

The principles of PANI-AuNPs $(6 \mathrm{~nm})$-GOx or Ppy-AuNPs $(6 \mathrm{~nm})$-GOx nanocomposites synthesis, their deposition on the surface of GR electrode with the following additional enrichment by GOx and electrochemical investigations are presented in Figure 1. In the presence of glucose and dissolved oxygen, GOx is able to generate gluconolactone and 
hydrogen peroxide, which is necessary to initiate monomer's polymerization reaction [35]. PMS is able to oxidize the reduced redox site $\left(\mathrm{FADH}_{2}\right)$ of GOx. Later, electrons from the reduced $\mathrm{PMSH}_{2}$ are transferred directly to the positively charged surface of GR electrode and/or through AuNPs present on the GR electrode [38].

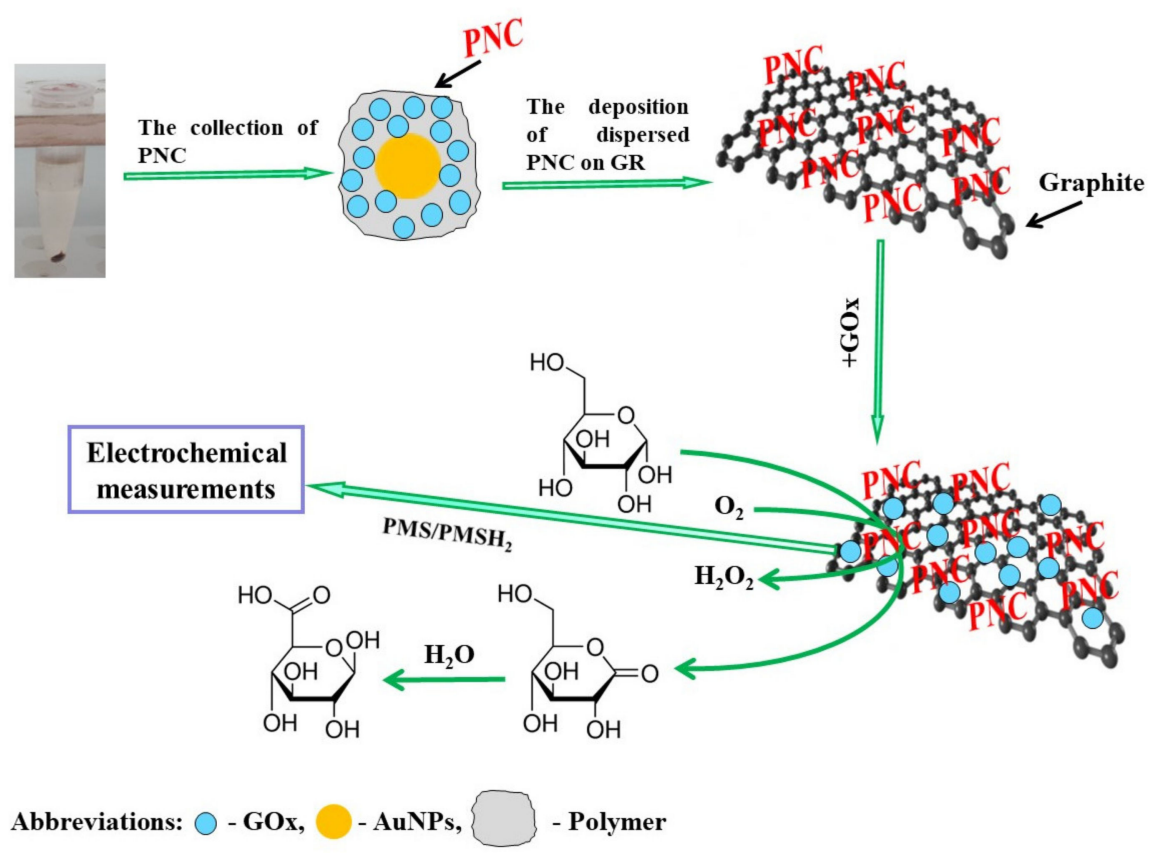

Figure 1. Schematic representation of the deposition of PANI-AuNPs $(6 \mathrm{~nm})^{-}-\mathrm{GOx}$ or Ppy-AuNPs $(6 \mathrm{~nm})^{-}$ GOx nanocomposites (PNC) on the surface of GR electrode with the following additional enrichment by GOx, and glucose determination by the developed enzymatic biosensors.

\section{Results and Discussion}

3.1. Characterization of Biosensors Based on GR/PANI-GOx/GOx, GR/Ppy-GOx/GOx, GR/PANI-AuNPs $(6$ nm $)-G O x / G O x$ or GR/Ppy-AuNPs $(6$ nm $)-G O x / G O x$ Electrodes by Cyclic Voltammetry

The form of cyclic votammograms and peak shifts are providing important information on the action mechanism and charge transfer of the electrochemical species [34]. The electrochemical behavior of glucose present on GR electrode, which is modified by PANI-GOx/GOx, Ppy-GOx/GOx, PANI-AuNPs $(6 \mathrm{~nm})^{-G O x} /$ GOx or Ppy-AuNPs (6 nm $^{-}$ GOx/GOx nanocomposites, was investigated in $0.05 \mathrm{~mol} \mathrm{~L}^{-1} \mathrm{SA}$ buffer, $\mathrm{pH}$ 6.0, with $0.01 \mathrm{~mol} \mathrm{~L}^{-1} \mathrm{KCl}$ in the presence of $6 \mathrm{mmol} \mathrm{L}^{-1}$ PMS by cyclic voltammetry in potential diapason from -0.60 to $+0.80 \mathrm{~V}$. To evaluate the influence of additionally on nanocomposite added GOx, the cyclic voltamperograms of GR/PANI-AuNPs ${ }_{(6 \mathrm{~nm})}$-GOx and GR/Ppy-AuNPs $(6 \mathrm{~nm})-\mathrm{GOx}$ were registered. As it is seen from Figure 2A,B, the redox reactions obtained on $\mathrm{CR}$ electrodes modified by polymer nanocomposites are reversible and are characterized by well-defined anodic and cathodic peaks. The potential of anodic peaks ( $\left.E_{\mathrm{pa}}\right)$ of GR electrodes modified by PANI-GOx/GOx, Ppy-GOx/GOx, PANI-AuNPs $(6 \mathrm{~nm})-\mathrm{GOx} / \mathrm{GOx}$ or Ppy-AuNPs $(6 \mathrm{~nm})-\mathrm{GOx} / \mathrm{GOx}$ composites was determined at $+0.12 \mathrm{~V}$ vs. $\left.\mathrm{Ag} / \mathrm{AgCl}_{(3 \mathrm{~mol} \mathrm{~L}}{ }^{-1} \mathrm{KCl}\right)$. The potential of cathodic peaks $\left(E_{\mathrm{pc}}\right)$ of GR electrode modified by PANI-GOx/GOx or Ppy-GOx/GOx was $-0.14 \mathrm{~V}$, while for PANI$\operatorname{AuNPs}_{(6 \mathrm{~nm})}-$ GOx/GOx and Ppy-AuNPs $(6 \mathrm{~nm})-$ GOx/GOx it was -0.17 and $-0.15 \mathrm{~V}$, respectively. Diffusion-controlled, reversible electrochemical process was observed: the peak separation $\left(\Delta E_{\mathrm{p}}=E_{\mathrm{pa}}-E_{\mathrm{pc}}\right)$ for PANI-GOx/GOx and Ppy-GOx/GOx was $0.26 \mathrm{~V}$, while for PANI-AuNPs $(6 \mathrm{~nm})^{-G O x} / \mathrm{GOx}$ and Ppy-AuNPs $(6 \mathrm{~nm}){ }^{-G O x} / \mathrm{GOx}$ it was 0.29 and $0.27 \mathrm{~V}$, respectively. This fact indicates that the reversibility was of high degree and both (PANI-AuNPs $(6 \mathrm{~nm})-\mathrm{GOx}$ and Ppy-AuNPs $(6 \mathrm{~nm})-\mathrm{GOx})$ polymer nanocomposites increased the efficiency of charge transfer between GOx and GR. 


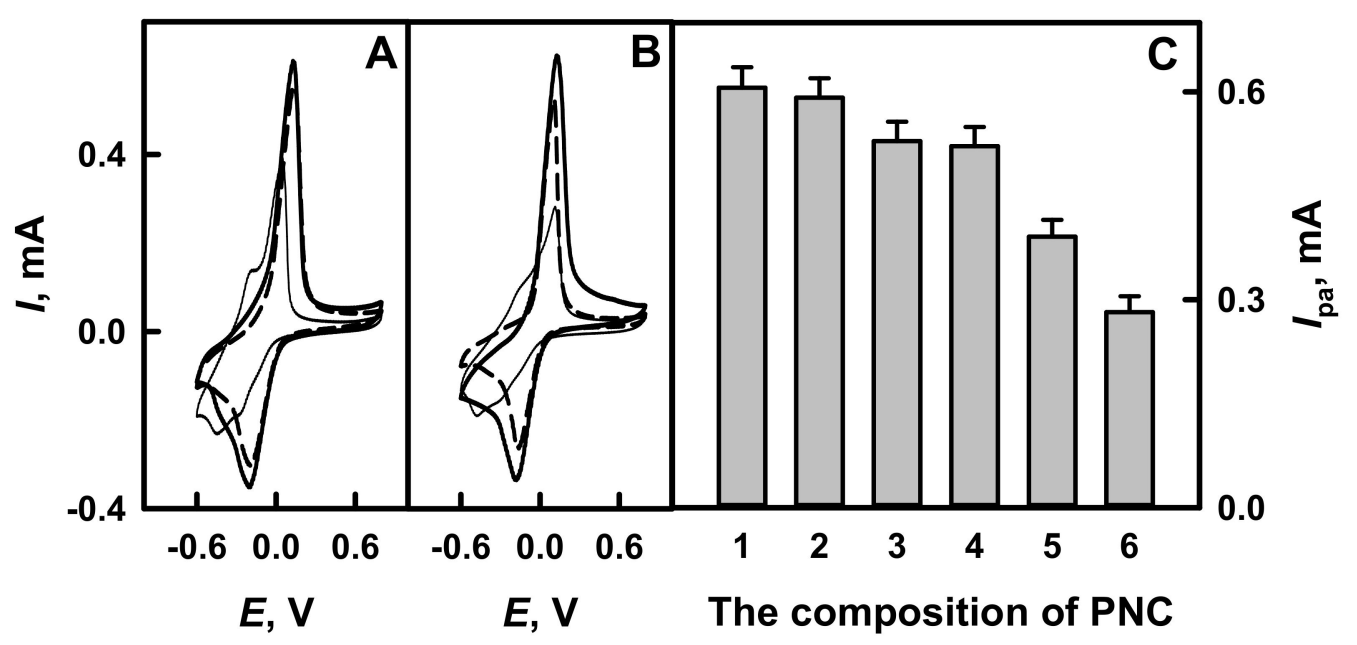

Figure 2. The cyclic voltammograms of GR electrode modified by PANI-GOx/GOx, PANI-AuNPs $(6 \mathrm{~nm})$-GOx/GOx or PANI-AuNPs $\left._{(6 \mathrm{~nm})}\right)^{-G O x}(\mathrm{~A})$, Ppy-GOx/GOx, Ppy-AuNPs $(6 \mathrm{~nm})$-GOx/GOx or Ppy-AuNPs $(6 \mathrm{~nm})^{-G O x}(\mathbf{B})$ and the diagrams of glucose biosensors based on GR electrodes modified by different composition of polymer nanocomposites (C). Conditions: (A,B) GR/PANI-GOx/GOx and GR/Ppy-GOx/GOx (dashed line), GR/PANI-AuNPs $(6 \mathrm{~nm}$ )-GOx/GOx and GR/Ppy-AuNPs $(6 \mathrm{~nm})-$ GOx/GOx (solid line), GR/PANI-AuNPs $(6 \mathrm{~nm})-G O x$ and GR/Ppy-AuNPs $(6 \mathrm{~nm})-$-GOx (thin line); (C) GR/Ppy-AuNPs $(6 \mathrm{~nm})$-GOx/GOx (1 column), GR/PANI-AuNPs ${ }_{(6 \mathrm{~nm})}$-GOx/GOx (2 column), GR/PANI-GOx/GOx (3 column), GR/Ppy-GOx/GOx (4 column), GR/PANI-AuNPs $(6 \mathrm{~nm})$-GOx (5 column) and GR/Ppy-AuNPs $(6 \mathrm{~nm}){ }^{-G O x}$ (6 column). Analytical signals were registered in $0.05 \mathrm{~mol} \mathrm{~L}^{-1} \mathrm{SA}$ buffer, $\mathrm{pH} 6.0$, with $0.01 \mathrm{~mol} \mathrm{~L}^{-1} \mathrm{KCl}_{\text {and }} 6.0 \mathrm{mmol} \mathrm{L}^{-1}$ PMS by cyclic voltammetry.

It was tentatively determined that glucose biosensors based on GR electrodes modified by GOx-containing nanocomposites are sensitive towards glucose. As is seen from Figure 2C, the presence of $\operatorname{AuNPs}_{(6 \mathrm{~nm})}$ in polyaniline- and polypyrrole-based nanocomposites (PANI-AuNPs $(6 \mathrm{~nm})-\mathrm{GOx} / \mathrm{GOx}$ and Ppy-AuNPs $(6 \mathrm{~nm})-\mathrm{GOx} / \mathrm{GOx})$ increased anodic current by 1.12 and 1.16 times, respectively, if compared with that registered for electrodes modified by PANI-GOx/GOx and Ppy-GOx/GOx. This fact indicates that AuNPs show good electrocatalytic activity towards electrochemical oxidation of glucose. The addition of GOx after electrode modification by polymer nanocomposites is recommended to increase the current response by 1.51 and 2.15 times for GR/PANI-AuNPs (6nm) $-\mathrm{GOx} / \mathrm{GOx}$ and GR/Ppy-AuNPs $(6 \mathrm{~nm})-\mathrm{GOx} / \mathrm{GOx}$ electrodes, in the comparison with results obtained using GR/PANI-AuNPs $(6 \mathrm{~nm})-\mathrm{GOx}$ and GR/Ppy-AuNPs $(6 \mathrm{~nm})-\mathrm{GOx}$ electrodes.

\subsection{The Influence of Polymer Nanocomposites Composition and Layer Thickness on the Current} Response Registered by Amperometry

The composition of polymer nanocomposites has a significant influence on the sensitivity and analytical characteristics of the here developed amperometric biosensors. Thoroughly, the influence of the composition of polymer-GOx nanocomposites with glucose oxidase without and with $\operatorname{AuNPs}_{(6 \mathrm{~nm})}$ was investigated in this chapter. To determine the advantages of polymer-GOx nanocomposites, the measurements were performed using GR electrodes modified by polymer nanocomposites of different composition: in the presence of GOx without and with $\operatorname{AuNPs}_{(6 \mathrm{~nm})}$. The investigations were performed in SA buffer, $\mathrm{pH}$ 6.0, with $0.01 \mathrm{~mol} \mathrm{~L}^{-1} \mathrm{KCl}$ and $6.0 \mathrm{mmol} \mathrm{L}^{-1}$ PMS.

The hyperbolic dependences of the current response registered by amperometry on the concentration of glucose in the diapason increased from 0.10 to $173 \mathrm{mmol} \mathrm{L}^{-1}$, and the influence of these kinds of compounds on the analytical response are presented in Figures 3 and $4 \mathrm{~A}$, respectively. As is seen from Figure 3, the registered hyperbolic dependences $\Delta I$ vs. glucose concentration were in agreement with the Michaelis-Menten kinetics. The difference of the maximal current response generated during the enzymatic reaction and the apparent Michaelis constant were correspondingly $a$ and $b$ parameters 
of the hyperbolic function $(y=a x /(b+x))$ and were used for the approximation of the obtained results.

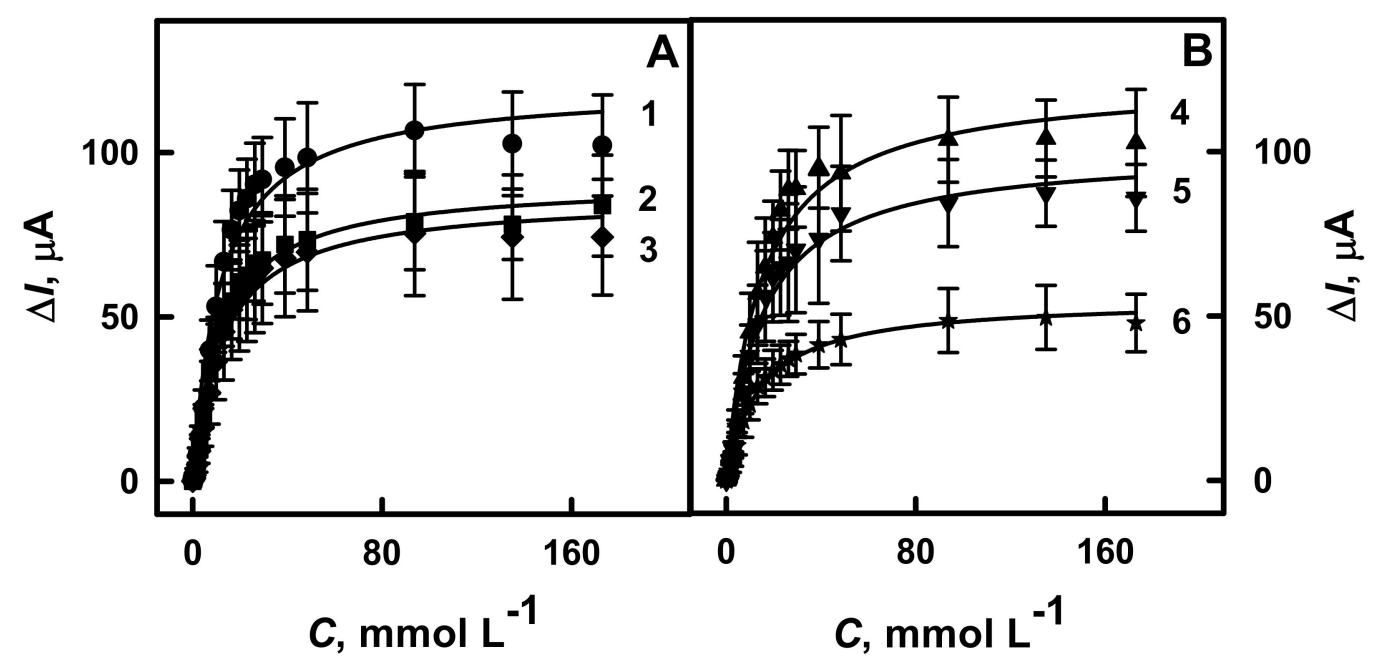

Figure 3. Calibration plots of glucose biosensors based on GR electrodes modified by polymer nanocomposites with the following additional enrichment by GOx: (A) PANI-AuNPs $(6 \mathrm{~nm})^{-G O x} / \mathrm{GOx}$ or PANI-GOx/GOx and (B) Ppy-AuNPs $(6 \mathrm{~nm})^{-}$ GOx/GOx and Ppy-GOx/GOx. Conditions: GR electrodes covered by PANI-AuNPs $(6 \mathrm{~nm})-\mathrm{GOx} / \mathrm{GOx}$ (1 line), PANIGOx/GOx (2 line), Ppy-AuNPs $(6 \mathrm{~nm})$-GOx/GOx (4 line) and Ppy-GOx/GOx (5 line). For comparison, GR electrodes modified with $\mathrm{AuNPs}_{(6 \mathrm{~nm})}$-GOx (3 line) and GOx (6 line) were investigated. Amperometric responses were registered in $0.05 \mathrm{~mol} \mathrm{~L}^{-1} \mathrm{SA}$ buffer, $\mathrm{pH}$ 6.0, with $0.01 \mathrm{~mol} \mathrm{~L}^{-1} \mathrm{KCl}$ and $6.0 \mathrm{mmol} \mathrm{L}^{-1}$ PMS.

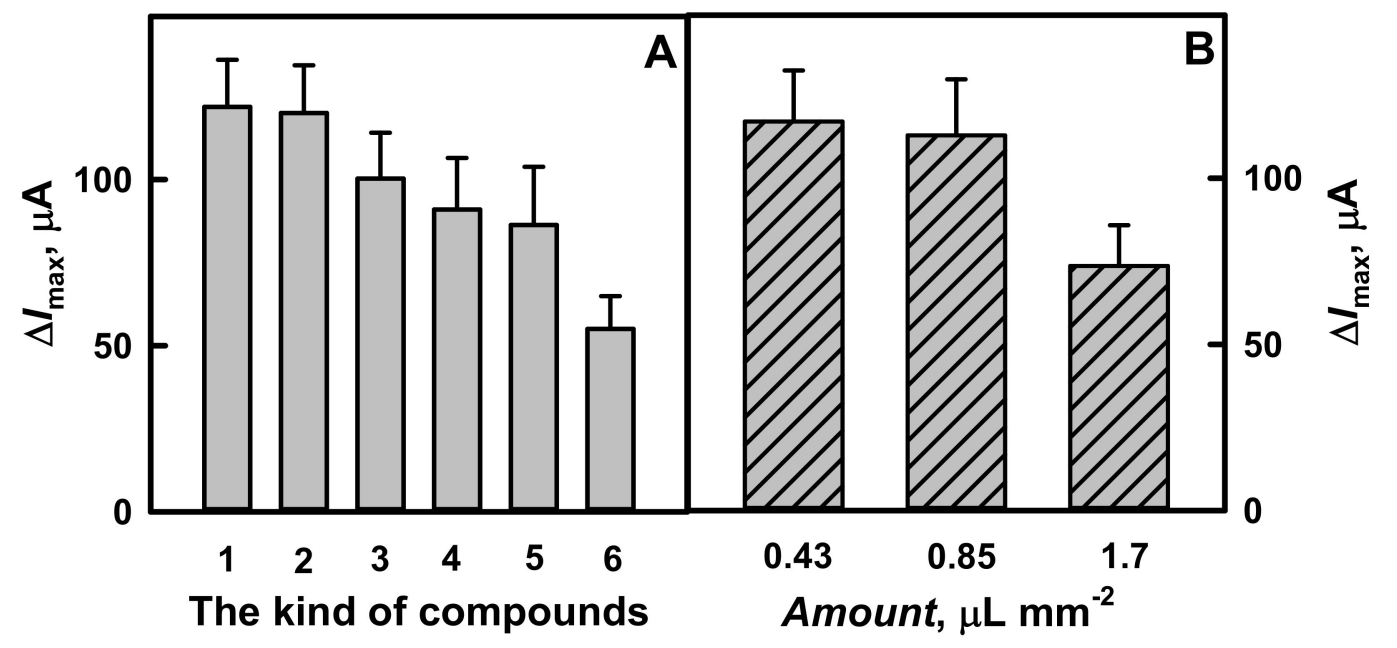

Figure 4. The diagrams of amperometric current response registered using GR electrodes (surface area $0.071 \mathrm{~cm}^{2}$ ) modified by: (A) different kind of compounds and (B) different amount of PANI-AuNPs $(6 \mathrm{~nm})$-GOx nanocomposites. Conditions: (A) GR/Ppy-AuNPs $(6 \mathrm{~nm})$-GOx/GOx (1 column), GR/PANI-AuNPs $(6 \mathrm{~nm})$-GOx/GOx (2 column), GR/Ppy-GOx/GOx (3 column), GR/PANI-GOx/GOx (4 column) electrodes; (B) GR/PANI-AuNPs $(6 \mathrm{~nm})$-GOx/GOx electrode. For comparison, $\mathrm{GR} / \mathrm{AuNPs}_{(6 \mathrm{~nm})}$-GOx (5 column) and GR/GOx (6 column) electrodes were used. Amperometric responses were registered in $0.05 \mathrm{~mol} \mathrm{~L}^{-1} \mathrm{SA}$ buffer, $\mathrm{pH} 6.0$, with $0.01 \mathrm{~mol} \mathrm{~L}^{-1} \mathrm{KCl}$ and $6.0 \mathrm{mmol} \mathrm{L}^{-1}$ PMS.

As is seen from Figures 3 and 4A, glucose biosensors based on GR electrode modified by polymer nanocomposites with GOx and $\operatorname{AuNPs}_{(6 \mathrm{~nm})}$ after additional enrichment by GOx are characterized by significantly higher sensitivity. The maximal current was higher for nanocomposites containing $\operatorname{AuNPs}_{(6 \mathrm{~nm})}$. Particularly for GR/Ppy / AuNPs $(6 \mathrm{~nm})^{-}$ GOx $/$ GOx $\left(\Delta I_{\max }=122 \mu \mathrm{A}\right)$ and GR/PANI $/ \operatorname{AuNPs}_{(6 \mathrm{~nm})}-\mathrm{GOx} / \mathrm{GOx}\left(\Delta I_{\max }=120 \mu \mathrm{A}\right)$ the current response increased by 1.22 and 1.32 times, respectively, if compared with results 
obtained using electrode modified by Ppy-GOx/GOx $\left(\Delta I_{\max }=100 \mu \mathrm{A}\right)$ or PANI-GOx/GOx $\left(\Delta I_{\max }=91.0 \mu \mathrm{A}\right)$. These results are in good agreement with that presented in previous investigations by cyclic voltammetry. Obtained results present the advantage of biosensors based on polymer nanocomposites, which contain $\mathrm{AuNPs}_{(6 \mathrm{~nm})}$ (Figure 4A). These results illustrate that $\Delta I_{\max }$ for GR electrodes modified by PANI-AuNPs $(6 \mathrm{~nm})-\mathrm{GOx} / \mathrm{GOx}$ or Ppy-AuNPs $(6 \mathrm{~nm})-\mathrm{GOx} / \mathrm{GOx}$ has increased by 1.39 and 1.41 times in the comparison with that registered by GR electrode modified only with $\operatorname{AuNPs}_{(6 \mathrm{~nm})}-\mathrm{GOx}\left(\Delta I_{\max }=86.3 \mu \mathrm{A}\right)$. The value of $\Delta I_{\max }$ determined for GR electrodes modified by PANI-GOx/GOx or PpyGOx/GOx was 1.65 and 1.81 times higher if compared with that determined for the electrode modified only by GOx $\left(\Delta I_{\max }=55.1 \mu \mathrm{A}\right)$.

High values of the apparent Michaelis constant determined for electrodes based on PANI-AuNPs $(6 \mathrm{~nm})-$ GOx/GOx and Ppy-AuNPs $(6 \mathrm{~nm})$-GOx/GOx show an increase linear detection range of glucose, which is the main advantage when the determination is performed directly in real samples. In our investigations, GR/PANI-AuNPs $(6 \mathrm{~nm})-\mathrm{GOx} / \mathrm{GOx}$,

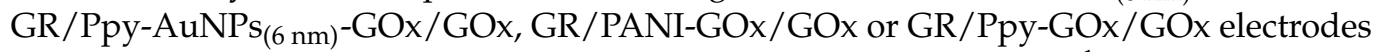
were characterized by $K_{\mathrm{M}}$ value of $15.1,11.7,14.9$ and $11.8 \mathrm{mmol} \mathrm{L}^{-1}$, respectively. According to another research, this effect indicates a strong affinity between the enzyme and glucose $[19,31]$. Therefore, PANI-AuNPs $(6 \mathrm{~nm})-\mathrm{GOx} / \mathrm{GOx}$ and Ppy-AuNPs $(6 \mathrm{~nm})-\mathrm{GOx} / \mathrm{GOx}$ were the most efficient and were used in further investigations.

The sensitivity of the designed biosensors depend on the composition of the polymer layer deposited on the surface of electrode. The influence of the thickness of polymer nanocomposites, which were deposited on GR electrodes, on the current response of the biosensor was investigated when different amounts of PANI-AuNPs $(6 \mathrm{~nm})-\mathrm{GOx}$ nanocomposites were equally distributed on GR electrode surface and the same amount of GOx was additionally immobilized over formed nanocomposite layer. As it is seen from the diagrams presented in Figure 4B, the difference of the maximal current response has decreased in the sequence-120, 119 and $76.9 \mu \mathrm{A}$, with an increase of the amount of PANI-AuNPs $(6 \mathrm{~nm})-\mathrm{GOx}$ nanocomposites of $0.43,0.85$ to $1.7 \mu \mathrm{L} \mathrm{mm}^{-2}$, respectively.

The value of $\Delta I_{\max }$ registered by GR electrodes modified by $0.43 \mu \mathrm{L} \mathrm{mm}^{-2}$ polymer nanocomposites was similar (only 1.01 times higher) to $0.85 \mu \mathrm{L} \mathrm{mm}^{-2}$ and 1.56 times higher than that obtained using $1.7 \mu \mathrm{L} \mathrm{mm}{ }^{-2}$ polymer nanocomposites. The decrease of $\Delta I_{\max }$ of the developed biosensor can be explained by the formation of a thick layer of PANI$\operatorname{AuNPs}_{(6 \mathrm{~nm})}$-GOx nanocomposites on GR electrode, which limits the diffusion of glucose to the surface of electrode. The lower amount of polymer nanocomposites than that of $0.43 \mu \mathrm{L} \mathrm{mm}^{-2}$ was not used in our system through similarity of the difference of maximal current for GR electrode modified by 0.85 or $1.7 \mu \mathrm{L} \mathrm{mm}^{-2}$ of polymer nanocomposites. In this way, the following investigations were performed in the presence of $0.43 \mu \mathrm{L} \mathrm{mm}^{-2}$ of polymer nanocomposites.

\subsection{The Evaluation of the Analytical Characteristics of GR Electrodes Modified by PANI-AuNPs $\left(6 n\right.$ nm) $-G O x / G O x, P p y-A u N P s_{(6 n m)}-G O x / G O x, P A N I-G O x / G O x$ or Ppy-GOx/GOx}

The next step of the research was dedicated to the evaluation of the analytical characteristics (linear range of glucose determination, correlation coefficient, sensitivity) and stability of the developed analytical systems. Firstly, the linear detection range of glucose determination was measured using GR electrode modified by PANI-AuNPs $(6 \mathrm{~nm})-\mathrm{GOx} / \mathrm{GOx}$, Ppy-AuNPs $(6 \mathrm{~nm})-\mathrm{GOx} / \mathrm{GOx}, \mathrm{PANI}-\mathrm{GOx} / \mathrm{GOx}$ or Ppy-GOx/GOx. As it is seen from the obtained calibration curves (Figure 5), the linear detection range of glucose for all investigated systems was up to $16.5 \mathrm{mmol} \mathrm{L}^{-1}$. The achieved linear detection range in our study was wider than for glucose biosensors based on carbon-ink/GOx modified stainless steel electrode (linear range up to $1 \mathrm{mmol} \mathrm{L}^{-1}$ ) [19], glassy carbon (GC) electrode modified by graphene/PANI/AuNPs/GOx (linear range up to $1.12 \mathrm{mmol} \mathrm{L}^{-1}$ ) [37] or graphene/nano$\mathrm{Au} / \mathrm{GOx}$ (linear range up to $3 \mathrm{mmol} \mathrm{L}{ }^{-1}$ ) [24]. It should be mentioned that only the linear range up to $0.7 \mathrm{mmol} \mathrm{L}^{-1}$ was registered using the GR electrode modified by the

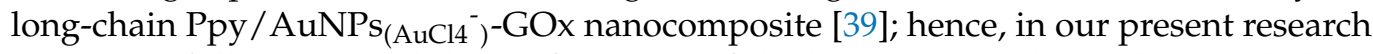
we successfully improved the performance of the biosensor applying dispersed short- 
chain conducting polymer nanocomposite with an additional layer of GOx. Additionally, the linear ranges for GR/PANI-AuNPs $(6 \mathrm{~nm})-\mathrm{GOx} / \mathrm{GOx}, \mathrm{GR} / \mathrm{Ppy}-\mathrm{AuNPs}_{(6 \mathrm{~nm})}-\mathrm{GOx} / \mathrm{GOx}$, GR/PANI-GOx/GOx and GR/Ppy-GOx/GOx were characterized by the correlation coefficient of $0.9968,0.9961,0.9927$ and 0.9977 , respectively (Table 1). As it is seen from Figure 5, the linear detection range of glucose is without the intercept on $x$ - or $y$-axis that indicates the suitability of the developed biosensors for analyte biosensing in biological samples.

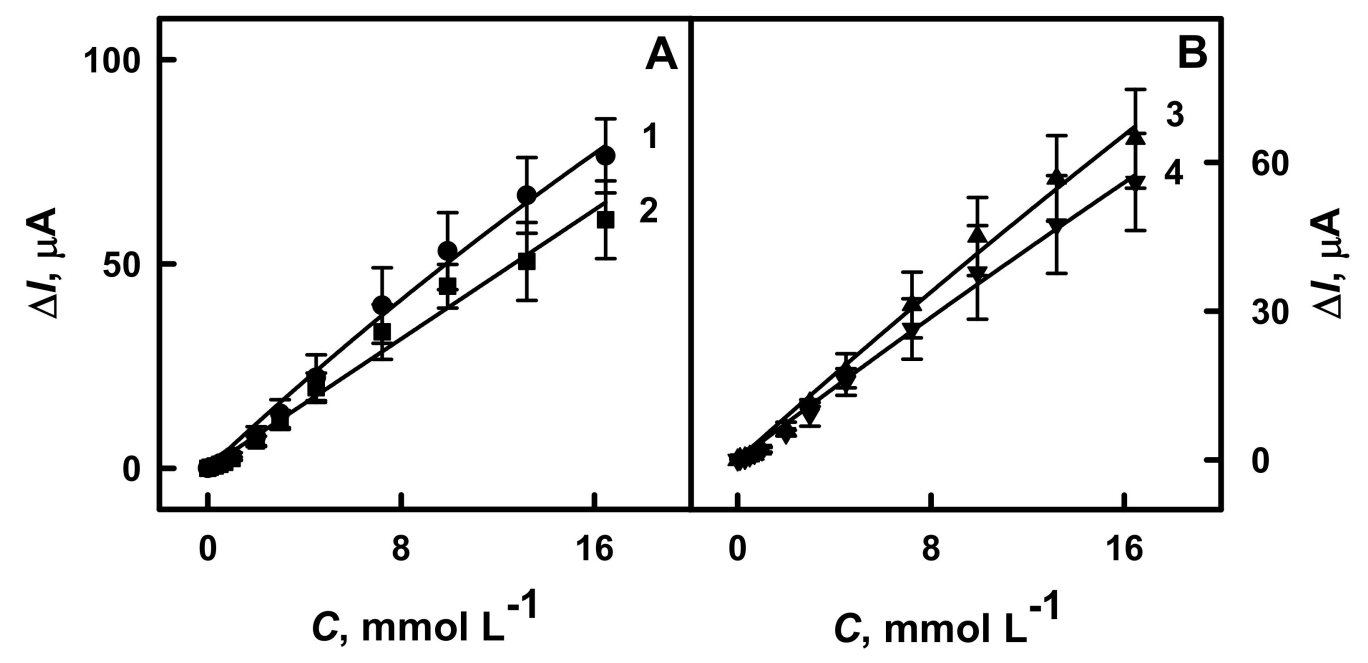

Figure 5. The linear detection range of biosensors based on GR electrodes modified by: (A) PANI-AuNPs $(6 \mathrm{~nm})-\mathrm{GOx} / \mathrm{GOx}$ (1 line) and PANI-GOx/GOx (2 line), (B) Ppy-AuNPs $(6 \mathrm{~nm})$-GOx/GOx (3 line) and Ppy-GOx/GOx (4 line). Conditions: amperometric responses were registered in $0.05 \mathrm{~mol} \mathrm{~L}^{-1} \mathrm{SA}$ buffer, $\mathrm{pH} 6.0$, with $0.01 \mathrm{~mol} \mathrm{~L}^{-1} \mathrm{KCl}_{\text {and }} 6.0 \mathrm{mmol} \mathrm{L}^{-1} \mathrm{PMS}$.

Table 1. The comparison of analytical characteristics of glucose biosensors based on GR/PANI-AuNPs $(6 \mathrm{~nm})-\mathrm{GOx} / \mathrm{GOx}$, GR/Ppy-AuNPs $(6 \mathrm{~nm})$-GOx/GOx, GR/PANI-GOx/GOx or GR/Ppy-GOx/GOx. All experimental conditions were the same as reported in Figure 5.

\begin{tabular}{|c|c|c|c|c|}
\hline $\begin{array}{l}\text { The Composition of Polymer } \\
\text { Nanocomposites on GR }\end{array}$ & $\begin{array}{c}\text { LOD, } \\
\text { mmol L }^{-1}\end{array}$ & $\begin{array}{c}\text { Sensitivity, } \\
\mu \mathrm{A} \mathrm{mM}^{-1} \mathrm{~cm}^{-2}\end{array}$ & $\begin{array}{l}\text { Linear Detection, } \\
\text { mmol L }\end{array}$ & $\begin{array}{l}\text { Correlation } \\
\text { Coefficient }\end{array}$ \\
\hline $\operatorname{PANI}^{-A u N P s}(6 \mathrm{~nm})-\mathrm{GOx} / \mathrm{GOx}$ & 0.070 & 65.4 & $0.10-16.5$ & 0.9968 \\
\hline Ppy-AuNPs (6nm)-GOx/GOx & 0.071 & 55.4 & $0.10-16.5$ & 0.9961 \\
\hline PANI-GOx/GOx & 0.084 & 52.0 & $0.10-16.5$ & 0.9936 \\
\hline Ppy-GOx/GOx & 0.10 & 48.0 & $0.10-16.5$ & 0.9977 \\
\hline
\end{tabular}

The sensitivity of the developed biosensors based on GR electrodes modified by

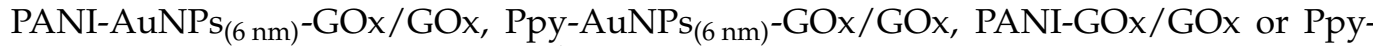
GOx/GOx towards $16.5 \mathrm{mmol} \mathrm{L}^{-1}$ of glucose was determined as 65.4, 55.4, 52.0 and $48.0 \mu \mathrm{A} \mathrm{mM}^{-1} \mathrm{~cm}^{-2}$, respectively (Table 1). The presence of $\operatorname{AuNPs}_{(6 \mathrm{~nm})}$ in the polymerization solution and in PANI-AuNPs $s_{(6 \mathrm{~nm})}$-GOx and Ppy-AuNPs $(6 \mathrm{~nm})$-GOx nanocomposites increased the sensitivity of glucose biosensor based on GR/PANI-AuNPs $(6 \mathrm{~nm})$-GOx/GOx or GR/Ppy-AuNPs $(6 \mathrm{~nm})-\mathrm{GOx} / \mathrm{GOx}$ by 1.26 and 1.15 times, respectively, if compared with results obtained for GR/PANI-GOx/GOx and GR/Ppy-GOx/GOx electrodes. Glucose biosensors based on GR electrodes modified by PANI-AuNPs $(6 \mathrm{~nm})-\mathrm{GOx} / \mathrm{GOx}$ or Ppy$\operatorname{AuNPs}_{(6 \mathrm{~nm})}-\mathrm{GOx} / \mathrm{GOx}$ are 5.61 and 4.76 times more sensitive than glucose biosensor based on GC/PLL/RGO-ZrO ${ }_{2}$ electrode ( $\left.11.65 \mu \mathrm{A} \mathrm{mM} \mathrm{m}^{-1} \mathrm{~cm}^{-2}\right)$ [23]. The sensitivity of the developed glucose biosensors based on GR/PANI-AuNPs $(6 \mathrm{~nm}){ }^{-G O x} / \mathrm{GOx}$ or GR/Ppy$\mathrm{AuNPs}_{(6 \mathrm{~nm})}$-GOx/GOx due to the use of another electrochemical method was very similar or a little bit smaller than that obtained in our previous study in the presence of long-chain Ppy / $\mathrm{AuNPs}\left(\mathrm{AuCl}^{-}\right)^{-} \mathrm{GOx}$ nanocomposite $\left(77.2 \mu \mathrm{A} \mathrm{mM}^{-1} \mathrm{~cm}^{-2}\right)$ [39]. The sensitivity of GR/Ppy-AuNPs $(6 \mathrm{~nm})$-GOx/GOx-based glucose biosensor developed in recent research 
is 2.55 times higher than the glucose biosensor based on $\mathrm{AuNP}_{(13 \mathrm{~nm})}$ electrochemically deposited on GR electrode and modified by GOx and Ppy $\left(21.7 \mu \mathrm{A} \mathrm{mM} \mathrm{mM}^{-1} \mathrm{~cm}^{-2}\right)$ [38]. Moreover, the sensitivity of the developed GR/Ppy-AuNPs $(6 \mathrm{~nm})-\mathrm{GOx} / \mathrm{GOx}$-based glucose biosensor is 18 times higher if compared with the glucose biosensor based on GC electrode modified by OOPpy $(300 \mathrm{~s})$-nanoAu and GOx $\left(3.07 \mu \mathrm{A} \mathrm{mM}^{-1} \mathrm{~cm}^{-2}\right)$ [29].

The repeatability of biosensors based on GR electrodes modified by PANI-AuNPs $\mathrm{s}_{(6 \mathrm{~nm})^{-}}$ GOx/GOx, Ppy-AuNPs $(6$ nm) - GOx/GOx, PANI-GOx/GOx or Ppy-GOx/GOx GR was investigated in the presence of $2.99 \mathrm{mmol} \mathrm{L}^{-1}$ of glucose. The relative standard deviations (RSD) calculated for these biosensors were $4.67 \%, 5.89 \%, 6.10 \%$ and $9.72 \%$, respectively. Developed glucose biosensors based on GR/PANI-AuNPs $(6 \mathrm{~nm})-\mathrm{GOx} / \mathrm{GOx}$ or GR/Ppy-AuNPs $(6 \mathrm{~nm})-\mathrm{GOx} / \mathrm{GOx}$ exhibited better repeatability (up to 3.0 and 2.4 times) than that obtained previously in the presence of long-chain polymer nanocomposites (for Ppy/AuNPs $\left(\mathrm{AuCl}^{-}\right)^{-}-\mathrm{GOx} \mathrm{RSD}$ was 13.9\%) [39]. The analytical response obtained using the developed in this paper glucose biosensor was two times faster than that obtained in our previous paper where long-chain polymer nanocomposites were used (20 s) [39]. As is seen from Table 1, the limit of detection for GR/PANI-AuNPs $(6 \mathrm{~nm})-\mathrm{GOx} / \mathrm{GOx}$ and GR/Ppy$\operatorname{AuNPs}_{(6 \mathrm{~nm})}$-GOx/GOx electrodes was almost similar -0.070 and $0.071 \mathrm{mmol} \mathrm{L}^{-1}$, respectively. Higher values of LOD for biosensors were determined using GR/PANI-GOx/GOx $\left(0.084 \mathrm{mmol} \mathrm{L}^{-1}\right)$ or GR/Ppy-GOx/GOx $\left(0.10 \mathrm{mmol} \mathrm{L}^{-1}\right)$ electrodes. Biosensors based on GR/PANI-AuNPs $(6 \mathrm{~nm})-\mathrm{GOx} / \mathrm{GOx}$ and GR/Ppy-AuNPs $(6 \mathrm{~nm})-\mathrm{GOx} / \mathrm{GOx}$ electrodes are characterized by lower LOD if compared with GR/PANI-GOx/GOx and GR/PpyGOx/GOx electrodes. The limit of detection determined for the developed biosensor based on short-chain PANI-AuNPs $s_{(6 \mathrm{~nm})}$-GOx composites with following immobilization of

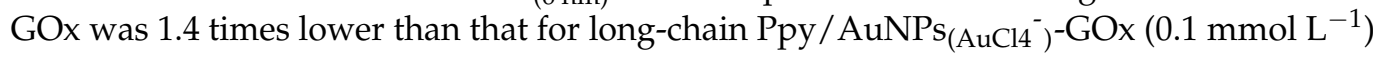
nanocomposite [39]. The LOD for biosensor based on Ppy-AuNPs $(6 \mathrm{~nm})-\mathrm{GOx} / \mathrm{GOx}$ electrode was 2.82 times lower if compared with previously developed biosensor based on electrochemically deposited $\operatorname{AuNPs}_{(13 \mathrm{~nm})}$, immobilized GOx and covered by Ppy (LOD $0.20 \mathrm{mmol} \mathrm{L}^{-1}$ ) [38].

3.4. The Stability of Glucose Biosensors Based on GR Electrodes Modified by

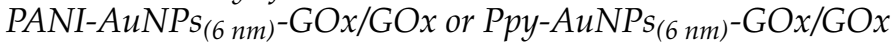

For the stability test, GR electrodes modified by PANI-AuNPs $(6 \mathrm{~nm})-\mathrm{GOx} / \mathrm{GOx}$ or Ppy-AuNPs $(6 \mathrm{~nm})$-GOx/GOx were stored at $+4{ }^{\circ} \mathrm{C}$ in a closed vessel hanging over SA buffer solution between electrochemical measurements for 131 days. The changes of analytical signal over time and the apparent Michaelis constant for the developed glucose biosensors are presented in Figure 6A,B, respectively.

As is seen from Figure $6 \mathrm{C}, \mathrm{D}$, the hyperbolic dependences of current responses on glucose concentration were in agreement with Michaelis-Menten kinetics. The analytical signal towards glucose for biosensors based on GR/PANI-AuNPs $s_{(6 \mathrm{~nm})}-\mathrm{GOx} / \mathrm{GOx}$ and GR/Ppy-AuNPs $(6 \mathrm{~nm})$-GOx/GOx electrodes considerably decreased during first 8 days, and $67.4 \%$ and $71.4 \%$ of initially current response was registered (Figure $6 \mathrm{~A}$ ). The decrease of current response might be explained by a low stability of the enzyme over time due to their denaturation and deactivation $[4,6]$. From 51 to 131 days, the current response of GR/PANI$\operatorname{AuNPs}_{(6 \mathrm{~nm})}-\mathrm{GOx} / \mathrm{GOx}$ and GR/Ppy-AuNPs $(6 \mathrm{~nm})-\mathrm{GOx} / \mathrm{GOx}$ electrodes towards glucose decreased from $31.8 \%$ down to $11.0 \%$ and from $24.4 \%$ down to $4.28 \%$, respectively. The $\tau_{1 / 2}$ values, which represent the time after that $50 \%$ of the initial current response is registered for glucose biosensors based on GR/PANI-AuNPs $(6 \mathrm{~nm})^{-\mathrm{GOx}} / \mathrm{GOx}$ or GR/Ppy-AuNPs $(6 \mathrm{~nm})^{-}$ GOx/GOx electrodes, were determined as 22 days and 17 days, respectively. These results illustrate that the biosensor based on GR/PANI/AuNPs $(6 \mathrm{~nm})-\mathrm{GOx} / \mathrm{GOx}$ electrode is 1.29 times more stable than that based on the GR/Ppy/AuNPs $(6 \mathrm{~nm})$-GOx/GOx electrode. 


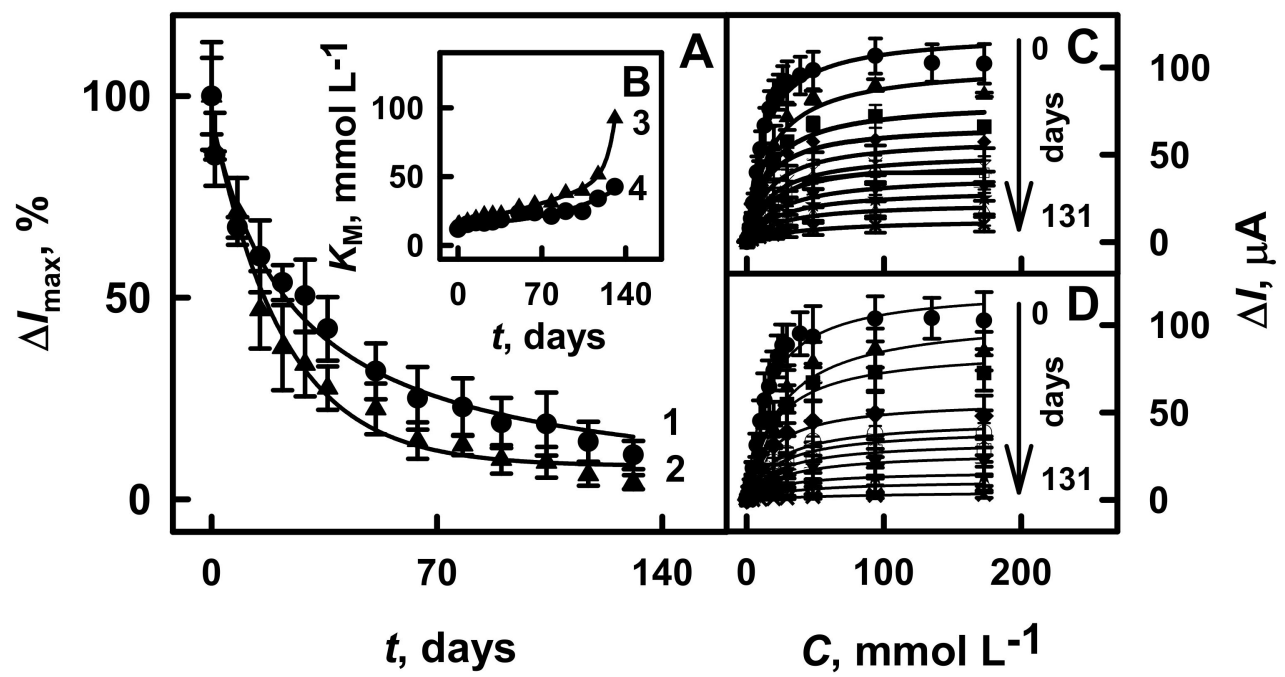

Figure 6. The changes of analytical signal (A), and the increase of the apparent Michaelis constant over time (B), calibration plots of glucose biosensors based on GR/PANI-AuNPs $(6 \mathrm{~nm})^{-G O x} / \mathrm{GOx}$ electrode $(\mathrm{C})$ and on GR/Ppy-AuNPs ${ }_{(6 \mathrm{~nm})^{-}}$ GOx/GOx electrode (D). Details of the presented calibration plots: GR/PANI-AuNPs $(6 \mathrm{~nm})$-GOx/GOx electrode ((A) line 1, (B) line 4, and (C) all lines) and GR/Ppy-AuNPs $(6 \mathrm{~nm})-\mathrm{GOx} / \mathrm{GOx}$ electrode ((A) line 2, (B) line 3 and (D) all lines). Amperometric responses were registered in $0.05 \mathrm{~mol} \mathrm{~L}^{-1} \mathrm{SA}$ buffer, $\mathrm{pH} 6.0$, with $0.01 \mathrm{~mol} \mathrm{~L}^{-1} \mathrm{KCl}_{\text {and }} 6.0 \mathrm{mmol} \mathrm{L}^{-1} \mathrm{PMS}$.

The developed glucose biosensor based on the GR electrode modified by PANI$\operatorname{AuNPs}_{(6 \mathrm{~nm})}-\mathrm{GOx} / \mathrm{GOx}$ was 3.14 times more stable than that of the Pt/PANI/gold nanorod composites/GOx electrode without mediator ( $\tau_{1 / 2}$ was determined as 7.0 days) [44]. The glucose biosensor based on the GR/Ppy-AuNPs $(6 \mathrm{~nm})-\mathrm{GOx} / \mathrm{GOx}$ electrode was 1.73 times more stable than that previously reported for biosensors based on the GR electrode with electrochemical deposited $\mathrm{AuNPs}_{(13 \mathrm{~nm})}$, immobilized GOx and modified by Ppy (9.8 days of $\tau_{1 / 2}$ ) [38]. In this paper, we developed a biosensor that is based on short-chain PANI-AuNPs $(6 \mathrm{~nm})$-GOx with a following immobilization of GOx that was by $17,6.7$ and 1.2 times more stable than the biosensor based on long-chain PANI/AuNPs $(6 \mathrm{~nm})$-GOx

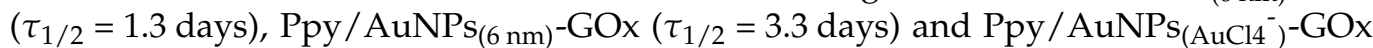
$\left(\tau_{1 / 2}=19\right.$ days) [39]. The higher stability of the biosensor is very important advantage.

The $K_{\mathrm{M}}$ constant increased from 15.4 to $92.3 \mathrm{mmol} \mathrm{L}^{-1}$ for the GR/PANI-AuNPs $(6 \mathrm{~nm})^{-}$ GOx/GOx electrode and from 12.9 to $42.4 \mathrm{mmol} \mathrm{L}^{-1}$ for the GR/Ppy-AuNPs $(6 \mathrm{~nm})-\mathrm{GOx} / \mathrm{GOx}$ electrode within the time frame ranging from 1 to 131 days (Figure 6B). It is seen that the value of the $K_{\mathrm{M}}$ for the GR electrode modified by Ppy-AuNPs $(6 \mathrm{~nm})-\mathrm{GOx} / \mathrm{GOx}$ after 131 days of electrode's storage stability was 2.18 times better than that determined for electrodes modified by PANI-AuNPs $(6 \mathrm{~nm})$-GOx/GOx. However, the higher value of $K_{\mathrm{M}}$ correlates with the decreased sensitivity of the biosensor. The glucose biosensor based on GR/PANI-AuNPs $(6 \mathrm{~nm})-\mathrm{GOx} / \mathrm{GOx}$ was selected for further investigation due to their rather good performance (high sensitivity and good stability, low LOD and good reproducibility (5.8\% for 11 measurements) (Figure S1 in the Supplementary Materials)). Additionally, this biosensor was applied for glucose determination in the serum sample.

\subsection{The Application of Biosensor Based on GR/PANI-AuNPs $(6 n m)$-GOx/GOx for Determination} of Glucose in Serum Samples

Glucose is considered as the most important sugar, which is always present in human's blood serum [21,45]. Other sugars such as fructose, mannose, galactose, xylose, and saccharose are considered stereoisomers of glucose and are characterized by the same molecular formula and sequence of bonded atoms, similar to the molecule of glucose [46]. Both AA and UA are antioxidants that are interfering during glucose biosensing through their influence on the response of the biosensor [44-49]. UA in a combination with another oxidant is able to generate radicals, which can promote various side reactions and damage 
of cells [48]. Meanwhile, the carboxylate group in polymer structures is able to decrease the penetration rate of negatively charged interfering compounds towards the electrode [44]. Therefore, such groups can increase the selectivity of sensors, which are used for the determination of glucose in samples that contain these compounds.

The selectivity tests of the glucose biosensor based on the GR/PANI-AuNPs $(6 \mathrm{~nm})^{-}$ GOx/GOx electrode to interfering and electroactive species were performed in $10 \times$ diluted serum samples. To evaluate the influence of sugars on the current response of the developed biosensor, the serum containing $10.0 \mathrm{mmol} \mathrm{L}^{-1}$ of glucose with the following addition of $1.00 \mathrm{mmol} \mathrm{L}^{-1}$ fructose, mannose, galactose, xylose and saccharose was tested (Figure 7A). As is seen from the obtained results, the developed glucose biosensor based on GR/PANI$\operatorname{AuNPs}_{(6 \mathrm{~nm})}$-GOx/GOx electrode was sensitive only to glucose.

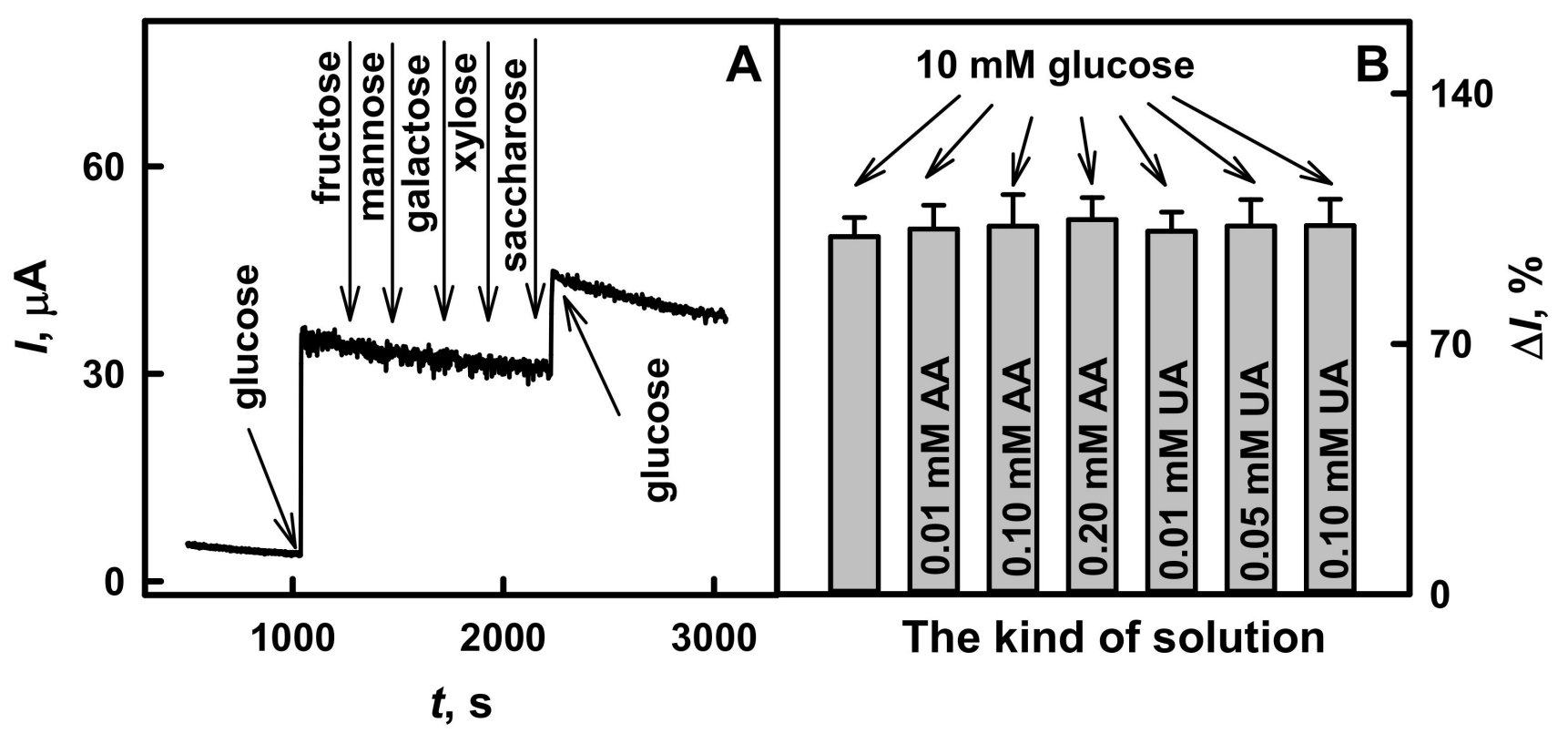

Figure 7. The influence of interfering species on the current response of glucose biosensor based on the GR/PANI$\operatorname{AuNPs}_{(6 \mathrm{~nm})}$-GOx/GOx electrode. Conditions: (A) amperogram registered in 10× diluted serum sample after the addition of $10.0 \mathrm{mmol} \mathrm{L}^{-1}$ glucose and $1.00 \mathrm{mmol} \mathrm{L}^{-1}$ of fructose, mannose, galactose, xylose or saccharose, (B) the diagram of registered current response in $10 \times$ diluted serum sample after the addition of $10.0 \mathrm{mmol} \mathrm{L}^{-1}$ glucose (first grey column without marking inside); of $10.0 \mathrm{mmol} \mathrm{L}^{-1}$ glucose with $0.01,0.10$ or $0.20 \mathrm{mmol} \mathrm{L}^{-1}$ of AA; of $10.0 \mathrm{mmol} \mathrm{L}^{-1}$ glucose with $0.01,0.05$ or $0.10 \mathrm{mmol} \mathrm{L}^{-1}$ of UA. Amperometric responses were registered in a $10 \times$ diluted sample of serum in the presence of $6 \mathrm{mmol} \mathrm{L}^{-1} \mathrm{PMS}$.

The influence of such electroactive species as AA and UA on the registered current response was investigated. The assessed concentrations of AA and UA were higher than their normal physiological concentrations: $0.141 \mathrm{mmol} \mathrm{L}^{-1}$ for AA [43,50] and $0.1 \mathrm{mmol} \mathrm{L}^{-1}$ for UA [47,51]. The results presented in Figure 7B illustrate that the addition of electroactive species has a moderate influence on the current response of the here evaluated glucose biosensor based on the GR/PANI-AuNPs $(6 \mathrm{~nm}){ }^{-G O x} / \mathrm{GOx}$ electrode. The addition of $10.0 \mathrm{mmol} \mathrm{L}^{-1}$ glucose with 0.01 and $0.10 \mathrm{mmol} \mathrm{L}^{-1}$ of AA increased the current response by $2.11 \%$ and $2.89 \%$, while the addition of $10.0 \mathrm{mmol} \mathrm{L}^{-1}$ glucose with $0.20 \mathrm{mmol} \mathrm{L}^{-1}$ of AA increased the current response by $4.74 \%$ if compared with current response after the addition of $10.0 \mathrm{mmol} \mathrm{L}^{-1}$ glucose without any AA. The presence of $0.01,0.05$ and $0.10 \mathrm{mmol} \mathrm{L}^{-1} \mathrm{UA}$ in the solution of $10.0 \mathrm{mmol} \mathrm{L}^{-1}$ glucose increased the current response of the developed biosensor by $1.49 \%, 2.99 \%$ and $3.08 \%$, respectively, in comparison with the results obtained after the addition of $10.0 \mathrm{mmol} \mathrm{L}-1$ glucose without any UA. The anti-interference capability of the developed glucose biosensor was higher than that described by other authors for the glucose biosensor based on GC electrode 
modified by graphene/nano-Au/GOx nanocomposites (the interference of $5.6 \%$ for AA and of $3.2 \%$ for UA was registered) [24]. If the obtained characteristics are compared with the previously published biosensor based on the long-chain Ppy/AuNPs $\left(\mathrm{AuCl}^{-}\right)^{-}$ GOx nanocomposites [39], it was shown that the developed glucose biosensor is 1.53 and 2.13 times more resistant to 0.01 or $0.10 \mathrm{mmol} \mathrm{L}^{-1}$ of $\mathrm{AA}$, and 1.47 and 4.48 times more resistant to 0.01 or $0.05 \mathrm{mmol} \mathrm{L}^{-1} \mathrm{UA}$. Just the insignificant interference of electroactive species indicates that the developed glucose biosensor based on GR/PANI-AuNPs $s_{(6 \mathrm{~nm})^{-}}$ GOx/GOx electrode is characterized by very good anti-interference ability towards the here evaluated interfering materials.

Glucose concentration of nondiabetic human's blood serum usually is in the range from 3 to $8 \mathrm{mmol} \mathrm{L}^{-1}$ [29,51,52], while for diabetic human's blood serum glucose concentration might be up to $30 \mathrm{mmol} \mathrm{L}^{-1}[3,11,29]$. The suitability of the designed biosensor based on the GR electrode modified by PANI-AuNPs $(6 \mathrm{~nm})-\mathrm{GOx} / \mathrm{GOx}$ for glucose determination in the diluted serum sample was assessed using the addition method. The results of the determined glucose concentration and the recovery are presented in Table 2. It was determined that the recovery ratios in this paper improved the enzymatic glucose biosensor in the serum samples from $95.0 \%$ to $98.5 \%$, which are similar to the results obtained using GC/OOPpy ${ }_{(300 \mathrm{~s})}$-nanoAu/GOx electrode (96\%) [29], and are better than the results obtained using the GR electrode directly modified by long-chain Ppy/ $\mathrm{AuNPs}_{\left(\mathrm{AuCl}^{-}\right)^{-}-\mathrm{GOx}}$ nanocomposites (92.7-94.8\%) [39].

Table 2. The determination and recovery ratio of glucose in the serum sample were investigated by biosensors based on the GR/PANI-AuNPs $(6 \mathrm{~nm})$-GOx/GOx electrode ( $n$-number of measurements, RSD—repeatability).

\begin{tabular}{cccc}
\hline $\begin{array}{c}\text { Added Concentration, } \\
\text { mol L-1 }\end{array}$ & $\begin{array}{c}\text { Detected Concentration, } \\
\text { mmol L }\end{array}$ & RSD, \% & $\begin{array}{c}\text { Recovery Ratio, } \\
\text { \% }\end{array}$ \\
\hline 0.10 & $0.095(4)$ & 8.13 & 95.0 \\
0.30 & $0.291(4)$ & 7.80 & 97.0 \\
0.50 & $0.490(4)$ & 4.99 & 98.0 \\
0.70 & $0.676(4)$ & 4.31 & 96.6 \\
1.00 & $0.972(4)$ & 5.42 & 97.2 \\
2.00 & $1.92(5)$ & 7.42 & 96.0 \\
4.48 & $4.40(4)$ & 7.09 & 98.2 \\
7.21 & $7.10(4)$ & 7.67 & 98.5 \\
\hline
\end{tabular}

Amperometric responses were measured in $10 \times$ diluted serum samples in the presence of $6 \mathrm{mmol} \mathrm{L}^{-1}$ PMS.

The analytical characteristics of glucose biosensor based on dispersed enzymatically synthesized PANI nanocomposites with following immobilization of GOx were improved in comparison to polymeric nanocomposites-based nanoparticles [39]. It should be noted that the advantages of the developed biosensor are: (i) high sensitivity $\left(65.4 \mu \mathrm{AmM}^{-1} \mathrm{~cm}^{-2}\right)$ and stability $\left(\tau_{1 / 2}=22\right.$ days), (ii) low limit of detection $\left(0.070 \mathrm{mmol} \mathrm{L}^{-1}\right)$, good reproducibility $(5.8 \%)$ and repeatability $(4.67 \%)$, (iii) wide linear range (up to $16.5 \mathrm{mmol} \mathrm{L}^{-1}$ ) and small amount of aliquot required for the analysis, (iv) multiple use and rather low price of single analysis, (v) fast analytical response (10 s), high resistance to interfering species (10.0 mmol L $\mathrm{m}^{-1}$ glucose with $0.01,0.10$ or $0.20 \mathrm{mmol} \mathrm{L}^{-1}$ of AA increased the current response by $2.11,2.89$ or $4.74 \% ; 10.0 \mathrm{mmol} \mathrm{L}^{-1}$ glucose with $0.01,0.05$ and $0.10 \mathrm{mmol} \mathrm{L}^{-1}$ UA increased the current response by $1.49,2.99$ and $3.08 \%$ ) and suitability for glucose determination (95.0-98.5\%). Thus, these characteristics allow the application of the developed biosensor for the determination of glucose in real samples.

\section{Conclusions}

In this research, we demonstrated the improved properties and analytical parameters of a glucose biosensor developed using dispersed nanocomposites based on GOx and $\operatorname{AuNPs}_{(6 \mathrm{~nm})}$ embedded within the conducting polymers PANI or Ppy. Biosensors with shorter polymeric chains are characterized by good reversibility of the soluble redox 
mediator. Our results show that the glucose biosensors based on GR/PANI-AuNPs $(6 \mathrm{~nm})^{-}$ GOx/GOx or GR/Ppy-AuNPs $(6 \mathrm{~nm})-G O x / G O x$ electrodes are characterized by high sensitivity, low limit of detection, wide linear range, good repeatability, sufficient storage stability. Additionally, the glucose biosensor based on GR/PANI-AuNPs $(6 \mathrm{~nm})-\mathrm{GOx} / \mathrm{GOx}$ electrode operates well in the serum sample and detects glucose in the presence of interfering species. This glucose biosensor enables the reduction of the amount of aliquot, which is required for the determination of the analyte. The methodology presented in this paper could be used for the design and fabrication of improved enzymatic biosensors for biomedical analysis. Further modification of GR/PANI-AuNPs $(6 \mathrm{~nm})-\mathrm{GOx} / \mathrm{GOx}$ or GR/Ppy-AuNPs $(6 \mathrm{~nm})-\mathrm{GOx} / \mathrm{GOx}$ electrodes by insoluble redox mediator will be the next step in this our research direction.

Supplementary Materials: The following are available online at https://www.mdpi.com/article/ 10.3390/polym13132173/s1, Figure S1: The reproducibility of enzymatic biosensors based on GR electrode modified by PANI-AuNPs $(6 \mathrm{~nm})^{-} \mathrm{GOx} / \mathrm{GOx}$ for $19.7 \mathrm{mmol} \mathrm{L}^{-1}$ of glucose concentration. Amperometric responses were registered in $0.05 \mathrm{~mol} \mathrm{~L}^{-1} \mathrm{SA}$ buffer, $\mathrm{pH}$ 6.0, with $0.01 \mathrm{~mol} \mathrm{~L}^{-1} \mathrm{KCl}$ and $6.0 \mathrm{mmol} \mathrm{L}^{-1}$ PMS.

Author Contributions: Conceptualization, A.R. (Almira Ramanaviciene) and N.G.; methodology, N.G.; software, N.G.; validation, N.G., A.R. (Almira Ramanaviciene), and A.R. (Arunas Ramanavicius); formal analysis, N.G.; investigation, N.G.; resources, A.R. (Arunas Ramanavicius); data curation, A.R. (Almira Ramanaviciene); writing - original draft preparation, N.G., A.R. (Almira Ramanaviciene) and A.R. (Arunas Ramanavicius); writing - review and editing, A.R. (Almira Ramanaviciene), A.R. (Arunas Ramanavicius); visualization, A.R. (Almira Ramanaviciene); supervision, A.R. (Almira Ramanaviciene); project administration, A.R. (Arunas Ramanavicius); funding acquisition, A.R. (Arunas Ramanavicius). All authors have read and agreed to the published version of the manuscript.

Funding: This research was funded by a grant (No. S-MIP-20-18) from the Research Council of Lithuania.

Institutional Review Board Statement: Not applicable.

Informed Consent Statement: Not applicable.

Data Availability Statement: Not applicable.

Conflicts of Interest: The authors declare no conflict of interest.

\section{References}

1. Batool, R.; Rhouati, A.; Nawaz, M.H.; Hayat, A.; Marty, J.L. A review of the construction of nano-hybrids for electrochemical biosensing of glucose. Biosensors 2019, 9, 46. [CrossRef]

2. Wang, H.C.; Lee, A.R. Recent developments in blood glucose sensors. J. Food Drug Anal. 2015, 23, 191-200. [CrossRef] [PubMed]

3. Heller, A.; Feldman, B. Electrochemical glucose sensors and their applications in diabetes management. Chem. Rev. 2008, 108, 2482-2505. [CrossRef]

4. Rocchitta, G.; Spanu, A.; Babudieri, S.; Latte, G.; Madeddu, G.; Galleri, G.; Nuvoli, S.; Bagella, P.; Demartis, M.I.; Fiore, V.; et al. Enzyme biosensors for biomedical applications: Strategies for safeguarding analytical performances in biological fluids. Sensors 2016, 16, 780. [CrossRef] [PubMed]

5. Labib, M.; Sargent, E.H.; Kelley, S.O. Electrochemical methods for the analysis of clinically relevant biomolecules. Chem. Rev. 2016, 116, 9001-9090. [CrossRef] [PubMed]

6. D'Orazio, P. Biosensors in clinical chemistry. Clin. Chim. Acta 2003, 334, 41-69. [CrossRef]

7. Khalil, I.; Julkapli, N.M.; Yehye, W.A.; Basirun, W.J.; Bhargava, S.K. Graphene-gold nanoparticles hybrid-synthesis, functionalization, and application in a electrochemical and surface-enhanced raman scattering biosensor. Materials 2016, 9, 406. [CrossRef] [PubMed]

8. Bo, X.; Zhou, M.; Guo, L. Electrochemical sensors and biosensors based on less aggregated graphene. Biosens. Bioelectron. 2017, 89, 167-186. [CrossRef]

9. Palanisamy, S.; Cheemalapati, S.; Chen, S.M. Amperometric glucose biosensor based on glucose oxidase dispersed in multiwalled carbon nanotubes/graphene oxide hybrid biocomposite. Mater. Sci. Eng. C 2014, 34, 207-213. [CrossRef]

10. Wang, J. Electrochemical glucose biosensors. Chem. Rev. 2008, 108, 814-825. [CrossRef] [PubMed]

11. Hill, C.; Carolina, N.; Pines, B.; Squibb, B.M.; Nordisk, N.; Nordisk, N.; Nordisk, N.; Nordisk, N.; Dickinson, B. La asociación española de la carretera entrega sus premios de periodismo. Carreteras 2006, 4, 120. 
12. Shu, H.; Cao, L.; Chang, G.; He, H.; Zhang, Y.; He, Y. Direct electrodeposition of gold nanostructures onto glassy carbon electrodes for non-enzymatic detection of glucose. Electrochim. Acta 2014, 132, 524-532. [CrossRef]

13. Menezes, F.G.; Neves, A.C.O.; de Lima, D.F.; Lourenço, S.D.; da Silva, L.C.; de Lima, K.M.G. Bioorganic concepts involved in the determination of glucose, cholesterol and triglycerides in plasma using the enzymatic colorimetric method. Quim. Nova 2015, 38, 588-594. [CrossRef]

14. Du Toit, H.; Di Lorenzo, M. Continuous power generation from glucose with two different miniature flow-through enzymatic biofuel cells. Biosens. Bioelectron. 2015, 69, 199-205. [CrossRef] [PubMed]

15. Babadi, A.A.; Bagheri, S.; Hamid, S.B.A. Progress on implantable biofuel cell: Nano-carbon functionalization for enzyme immobilization enhancement. Biosens. Bioelectron. 2016, 79, 850-860. [CrossRef]

16. Ramanavicius, S.; Ramanavicius, A. Conducting polymers in the design of biosensors and biofuel cells. Polymers 2021, 13, 49. [CrossRef]

17. Ramanavicius, S.; Ramanavicius, A. Charge transfer and biocompatibility aspects in conducting polymer-based enzymatic biosensors and biofuel cells. Nanomaterials 2021, 11, 371. [CrossRef] [PubMed]

18. Ramanavicius, S.; Ramanavicius, A. Progress and insights in the application of MXenes as new 2d nano-materials suitable for biosensors and biofuel cell design. Int. J. Mol. Sci. 2020, 21, 9224. [CrossRef] [PubMed]

19. Rama, E.C.; Costa-García, A.; Fernández-Abedul, M.T. Pin-based electrochemical glucose sensor with multiplexing possibilities. Biosens. Bioelectron. 2017, 88, 34-40. [CrossRef]

20. Abdulbari, H.A.; Basheer, E.A.M. Electrochemical biosensors: Electrode development, materials, design, and fabrication. ChemBioEng Rev. 2017, 4, 92-105. [CrossRef]

21. Galant, A.L.; Kaufman, R.C.; Wilson, J.D. Glucose: Detection and analysis. Food Chem. 2015, 188, 149-160. [CrossRef]

22. Zhu, C.; Yang, G.; Li, H.; Du, D.; Lin, Y. Electrochemical sensors and biosensors based on nanomaterials and nanostructures. Anal. Chem. 2015, 87, 230-249. [CrossRef]

23. Vilian, A.T.E.; Chen, S.M.; Ali, M.A.; Al-Hemaid, F.M.A. Direct electrochemistry of glucose oxidase immobilized on $\mathrm{ZrO}_{2}$ nanoparticles-decorated reduced graphene oxide sheets for a glucose biosensor. RSC Adv. 2014, 4, 30358-30367. [CrossRef]

24. Wang, X.; Zhang, X. Electrochemical co-reduction synthesis of graphene/nano-gold composites and its application to electrochemical glucose biosensor. Electrochim. Acta 2013, 112, 774-782. [CrossRef]

25. Bartlett, P.N.; Al-Lolage, F.A. There is no evidence to support literature claims of direct electron transfer (DET) for native glucose oxidase (GOx) at carbon nanotubes or graphene. J. Electroanal. Chem. 2018, 819, 26-37. [CrossRef]

26. Luckarift, H.R.; Ivnitski, D.; Rincón, R.; Atanassov, P.; Johnson, G.R. Glucose oxidase catalyzed self-assembly of bioelectroactive gold nanostructures. Electroanalysis 2010, 22, 784-792. [CrossRef]

27. Feng, D.; Wang, F.; Chen, Z. Electrochemical glucose sensor based on one-step construction of gold nanoparticle-chitosan composite film. Sens. Actuators B Chem. 2009, 138, 539-544. [CrossRef]

28. German, N.; Kausaite-Minkstimiene, A.; Ramanavicius, A.; Semashko, T.; Mikhailova, R.; Ramanaviciene, A. The use of different glucose oxidases for the development of an amperometric reagentless glucose biosensor based on gold nanoparticles covered by polypyrrole. Electrochim. Acta 2015, 169, 326-333. [CrossRef]

29. Haghighi, B.; Tabrizi, M.A. Direct electron transfer from glucose oxidase immobilized on an overoxidized polypyrrole film decorated with Au nanoparticles. Colloids Surf. B Biointerfaces 2013, 103, 566-571. [CrossRef]

30. Liu, S.; Leech, D.; Ju, H. Application of colloidal gold in protein immobilization, electron transfer, and biosensing. Anal. Lett. 2003, 36, 1-19. [CrossRef]

31. Zhang, C.; Zhang, Y.; Miao, Z.; Ma, M.; Du, X.; Lin, J.; Han, B.; Takahashi, S.; Anzai, J.I.; Chen, Q. Dual-function amperometric sensors based on poly(diallydimethylammoniun chloride)-functionalized reduced graphene oxide/manganese dioxide/gold nanoparticles nanocomposite. Sens. Actuator B Chem. 2016, 222, 663-673. [CrossRef]

32. Freund, M.S.; Deore, B.A. Self-Doped Conducting Polymers; John Wiley \& Sons: Hoboken, NK, USA, 2007 ; Volume 2002.

33. Oztekin, Y.; Ramanaviciene, A.; Yazicigil, Z.; Solak, A.O.; Ramanavicius, A. Direct electron transfer from glucose oxidase immobilized on polyphenanthroline-modified glassy carbon electrode. Biosens. Bioelectron. 2011, 26, 2541-2546. [CrossRef] [PubMed]

34. Le, T.H.; Kim, Y.; Yoon, H. Electrical and electrochemical properties of conducting polymers. Polymers 2017, 9. [CrossRef] [PubMed]

35. Ramanaviciene, A.; Schuhmann, W.; Ramanavicius, A. AFM study of conducting polymer polypyrrole nanoparticles formed by redox enzyme - glucose oxidase - initiated polymerisation. Colloids Surf. B Biointerfaces 2006, 48, 159-166. [CrossRef] [PubMed]

36. German, N.; Popov, A.; Ramanaviciene, A.; Ramanavicius, A. Evaluation of enzymatic formation of polyaniline nanoparticles. Polymer 2017, 115, 211-216. [CrossRef]

37. Xu, Q.; Gu, S.X.; Jin, L.; Zhou, Y.E.; Yang, Z.; Wang, W.; Hu, X. Graphene/polyaniline/gold nanoparticles nanocomposite for the direct electron transfer of glucose oxidase and glucose biosensing. Sens. Actuators B Chem. 2014, 190, 562-569. [CrossRef]

38. German, N.; Ramanavicius, A.; Ramanaviciene, A. Amperometric glucose biosensor based on electrochemically deposited gold nanoparticles covered by polypyrrole. Electroanalysis 2017, 29. [CrossRef]

39. German, N.; Ramanaviciene, A.; Ramanavicius, A. Formation and electrochemical evaluation of polyaniline and polypyrrole nanocomposites based on glucose oxidase and gold nanostructures. Polymers 2020, 12, 3026. [CrossRef] 
40. German, N.; Ramanaviciene, A.; Ramanavicius, A. Formation of Polyaniline and Polypyrrole Nanocomposites with Embedded Glucose Oxidase and Gold Nanoparticles. Polymers 2019, 11, 377. [CrossRef]

41. German, N.; Popov, A.; Ramanaviciene, A.; Ramanavicius, A. Formation and electrochemical characterisation of enzyme-assisted formation of polypyrrole and polyaniline nanocomposites with embedded glucose oxidase and gold nanoparticles. J. Electrochem. Soc. 2020, 167, 165501. [CrossRef]

42. German, N.; Popov, A.; Ramanaviciene, A.; Ramanavicius, A. Enzymatic formation of polyaniline, polypyrrole, and polythiophene nanoparticles with embedded glucose oxidase. Nanomaterials 2019, 9, 806. [CrossRef] [PubMed]

43. Singh, S.; Solanki, P.R.; Pandey, M.K.; Malhotra, B.D. Covalent immobilization of cholesterol esterase and cholesterol oxidase on polyaniline films for application to cholesterol biosensor. Anal. Chim. Acta 2006, 568, 126-132. [CrossRef]

44. Tamer, U.; Seçkin, A.İ.; Temur, E.; Torul, H. Fabrication of biosensor based on polyaniline/gold nanorod composite. Int. J. Electrochem. 2011, 2011, 1-7. [CrossRef]

45. Amor-Gutiérrez, O.; Costa Rama, E.; Costa-García, A.; Fernández-Abedul, M.T. Paper-based maskless enzymatic sensor for glucose determination combining ink and wire electrodes. Biosens. Bioelectron. 2017, 93, 40-45. [CrossRef] [PubMed]

46. Kim, I.; Kwon, D.; Lee, D.; Lee, T.H.; Lee, J.H.; Lee, G.; Yoon, D.S. A highly permselective electrochemical glucose sensor using red blood cell membrane. Biosens. Bioelectron. 2018, 102, 617-623. [CrossRef] [PubMed]

47. Psychogios, N.; Hau, D.D.; Peng, J.; Guo, A.C.; Mandal, R.; Bouatra, S.; Sinelnikov, I.; Krishnamurthy, R.; Eisner, R.; Gautam, B.; et al. The human serum metabolome. PLoS ONE 2011, 6. [CrossRef]

48. Sautin, Y.Y.; Johnson, R.J. Uric acid: The oxidant-antioxidant paradox. Nucleosides Nucleotides Nucleic Acids 2008, 27, 608-619. [CrossRef]

49. Cho, J.; Ahn, S.; Yim, J.; Cheon, Y.; Jeong, H.; Lee, S.-G.; Kim, J.-H. Letter to the editor clinical chemistry influence of vitamin C and maltose on the accuracy of three models of glucose meters. Ann. Lab. Med. 2016, 36, 271-274. [CrossRef]

50. Koch, P.; Sidloi, M.; Tonks, D.B. Estimation of serum ascorbic acid in patients and the effect of ascorbic acid and its oxidation products on SMA 12/60 parameters. Clin. Biochem. 1980, 13, 73-77. [CrossRef]

51. Rong, L.Q.; Yang, C.; Qian, Q.Y.; Xia, X.H. Study of the nonenzymatic glucose sensor based on highly dispersed Pt nanoparticles supported on carbon nanotubes. Talanta 2007, 72, 819-824. [CrossRef] [PubMed]

52. Li, Y.; Song, Y.Y.; Yang, C.; Xia, X.H. Hydrogen bubble dynamic template synthesis of porous gold for nonenzymatic electrochemical detection of glucose. Electrochem. Commun. 2007, 9, 981-988. [CrossRef] 